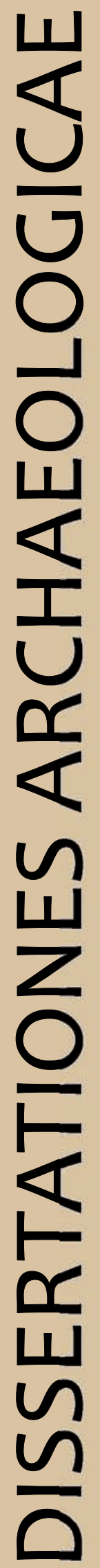

ex Instituto Archaeologico Universitatis de Rolando Eötvös nominatae

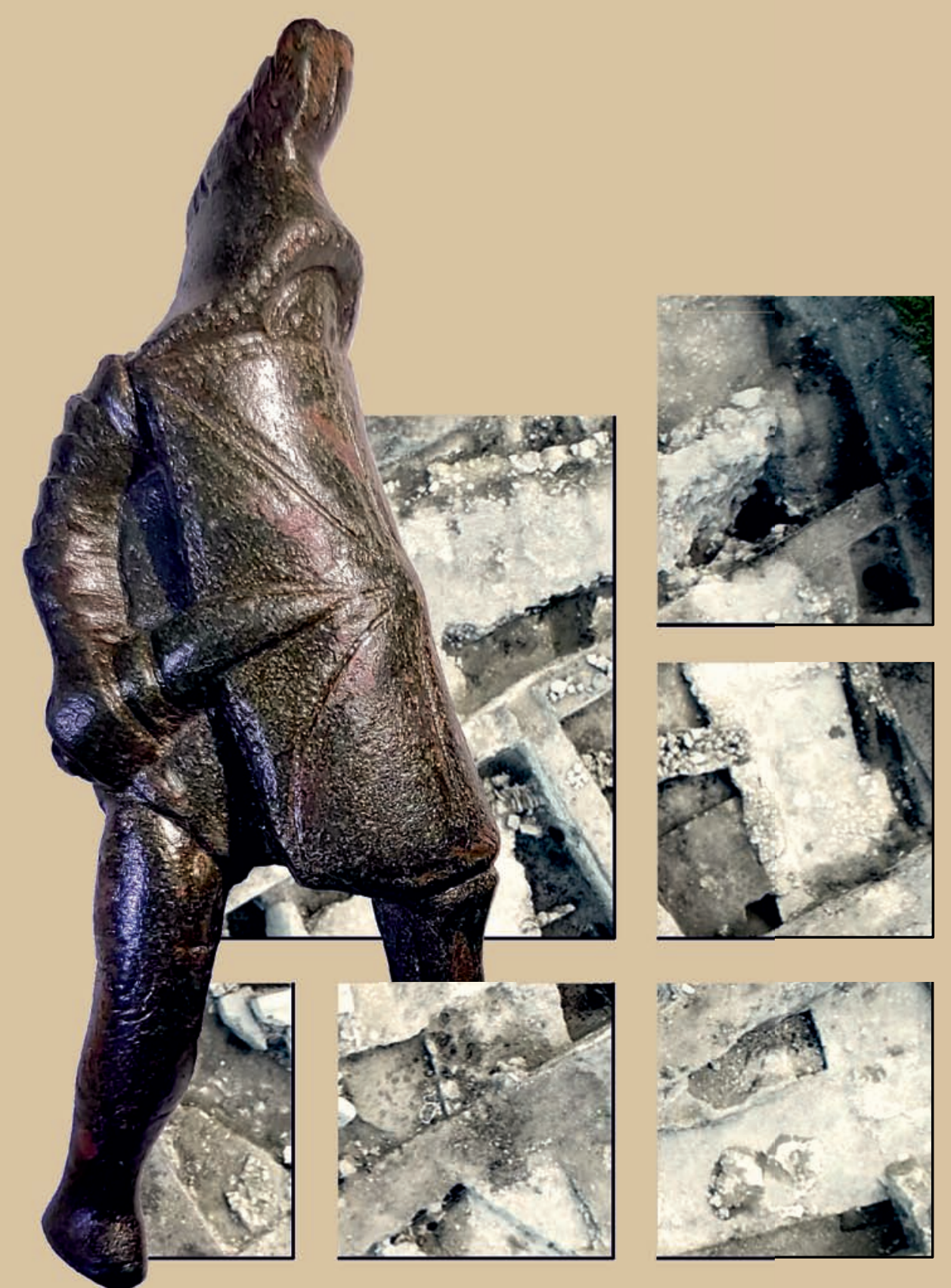

$$
\text { Ser. 3. No. 7. } 2019
$$




\section{Dissertationes Archaeologicae ex Instituto Archaeologico}

Universitatis de Rolando Eötvös nominatae Ser. 3. No. 7.

Budapest 2019 
Dissertationes Archaeologicae ex Instituto Archaeologico Universitatis de Rolando Eötvös nominatae

Ser. 3. No. 7.

Editor-in-chief:

DÁvid BARTUS

Editorial board:

LÁsZló BARTOSIEWICZ

LÁSZLÓ BORHY

ZOLTÁN CZAJLIK

IsTVÁN FELD

GÁBOR KALLA

PÁL RACZKY

MikLÓs SzABÓ

TivadAR VidA

Technical editor:

GÁBOR VÁCZI

Proofreading:

SZILVIA BARTUS-SZÖLLősI

ZsóFIA KondÉ

Aviable online at http://dissarch.elte.hu

Contact: dissarch@btk.elte.hu

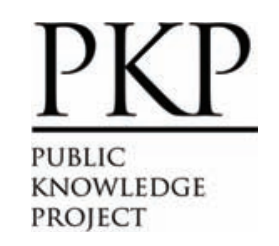

๑ ELTE Eötvös Loránd University, Institute of Archaeological Sciences

Layout and cover design: Gábor Váczi

Budapest 2019 


\section{CONTENTs}

\section{ARticles}

János Gábor TARBAY

The Casting Mould and the Wetland Find - New Data on the Late Bronze Age

Peschiera Daggers

Máté MeRvel

Late Bronze Age stamp-seals with negative impressions of seeds from Eastern Hungary

János Gábor TARBAY

Melted Swords and Broken Metal Vessels - A Late Bronze Age Assemblage

from Tatabánya-Bánhida and the Selection of Melted Bronzes

Ágnes ScHNEIDER

Multivariate Statistical Analysis of Archaeological Contexts: the case study

of the Early La Tène Cemetery of Szentlörinc, Hungary

Csilla SÁRÓ - Gábor LASSÁNYI

Bow-tie shaped fibulae from the cemetery of Budapest/Aquincum-Graphisoft Park

Dávid BARTus

Roman bronze gladiators - A new figurine of a murmillo from Brigetio

Kata DÉvAI

Re-Used Glass Fragments from Intercisa

Bence Simon

Rural Society, Agriculture and Settlement Territory in the Roman, Medieval and Modern Period Pilis Landscape

Rita RAKONCZAY

„Habaner“ Ofenkacheln auf der Burg Čabrad”

\section{FIELD REPORT}

Bence Simon - Anita Benes - Szilvia Joháczi - Ferenc BARnA

New excavation of the Roman Age settlement at Budapest dist. XVII, Péceli út (15127) site 


\section{Thesis Abstracts}

Kata SzILÁGYi

Die Silexproduktion im Kontext der Südosttransdanubischen Gruppe

der spätneolithischen Lengyel-Kultur

Norbert FARAGÓ

Complex, household-based analysis of the stone tools of Polgár-Csőszhalom

János Gábor TARBAY

Type Gyermely Hoards and Their Dating - A Supplemented Thesis Abstract

Zoltán Havas

The brick architecture of the governor's palace in Aquincum

Szabina Merva

'...circa Danubium...' from the Late Avar Age until the Early Árpádian Age-

$8^{\text {th }}-11^{\text {th }}$-Century Settlements in the Region of the Central Part of the Hungarian

Little Plain and the Danube Bend

Szabolcs Balázs NAGY

Noble Residences in the $15^{\text {th }}$ century Hungarian Kingdom - The Castles of Várpalota,

Ujlak and Kisnána in the Light of Architectural Prestige Representation

Ágnes KollátH

Tipology and Chronology of the early modern pottery in Buda 


\title{
„Habaner“ Ofenkacheln auf der Burg Čabrad”
}

\author{
RITA RAKONCZAY \\ Institut für Archäologie \\ ELTE Eötvös Loránd Universität \\ Europäisches Burgeninstitut \\ Deutsche Burgenvereinigung \\ rita.rakonczay@gmail.com
}

\begin{abstract}
Abstrakte
Im Gebiet des ehemaligen Königreichs Ungarn gehören vier, komplett erhaltenen Öfen mit blauen und weißen Glasuren zu den ältesten ungarischen Heizanlagen, die von der Forscher als Habanerprodukt identifiziert wurden. Obwohl ein komplett erhaltener Ofen in der ungarischen Kachelofenforschung eine Seltenheit darstellt, bekamen die Verhältnisse, die Ursprünge oder die Datierung der Öfen keine bedeutende Rolle in Untersuchungen. Die Öfen haben sich in Sammlungen erhalten, deswegen konnten die archäologischen Ergebnisse bei diesen Fragen auch nicht helfen. Auf der Burg Čabrad'kamen aber Ofenkacheln vor, die sich zu den Öfen ähneln, aber sie stammen aus der mit Münzen datierten Schichtenreihe. In dieser Art und Weise könnten die archäologischen Methoden bei der Datierung und bei der Untersuchung der erhaltenen Öfen auch helfen.
\end{abstract}

\section{Einleitung}

Im Gebiet des ehemaligen Königreichs Ungarn ist eine Tendenz in der Forschung zu erkennen, jede Keramikscherbe mit weißer und blauer Glasur - entweder ein Geschirrfragment oder ein Kachelstück - den Habanern zuzuordnen. Zu den frühesten, komplett erhaltenen ungarischen Öfen gehören vier, mit weißer und blauer Zinnglasur verzierte Heizanlagen, die seit jeher als Habaneröfen interpretiert werden. ${ }^{1}$ Die Öfen von Trstené (Liptónádasd) heute im Ungarischen Nationalmuseum Budapest (Abb. 1.1) -, von Neusohl (Banská Bystrica/ Besztercebánya) - heute im Kunstgewerbemuseum Budapest ( $A b b$. 1.2) -, von der Zipser Burg (Spíš/Szepes) - heute auf der Burg Krásna Hôrka (Krasznahorka) (Abb. 1.3) - und von der Bibersburg (Červený Kameň/Vöröskő) - heute im Schloss Weinitz (Bojnice, Bajmóc) $(A b b .1 .4)$ - haben sich in Sammlungen erhalten. Ihre Herkunft oder ihr Herstellungsort sind jedoch noch nicht sicher geklärt, obwohl die kunsthistorische Forschung sie zu identifizieren versuchte. ${ }^{2}$ Die bei Ausgrabungen gefundenen Ofenkacheln aus der Burg Čabrad sind daher besonders wichtig, weil die ergrabenen Kacheltypen zu den erwähnten Öfen passen und sie aus einer durch Münzen und Keramik datierten Fundschicht stammen. ${ }^{3}$ Die archäologischen Ergebnisse helfen deshalb bei der Datierung.

1 LANDSFELD 1970, 23.

2 Ridovics et al. 2015.

3 Über die Ausgrabung: BeLjak et al. 2016; RAKonczay 2018. 

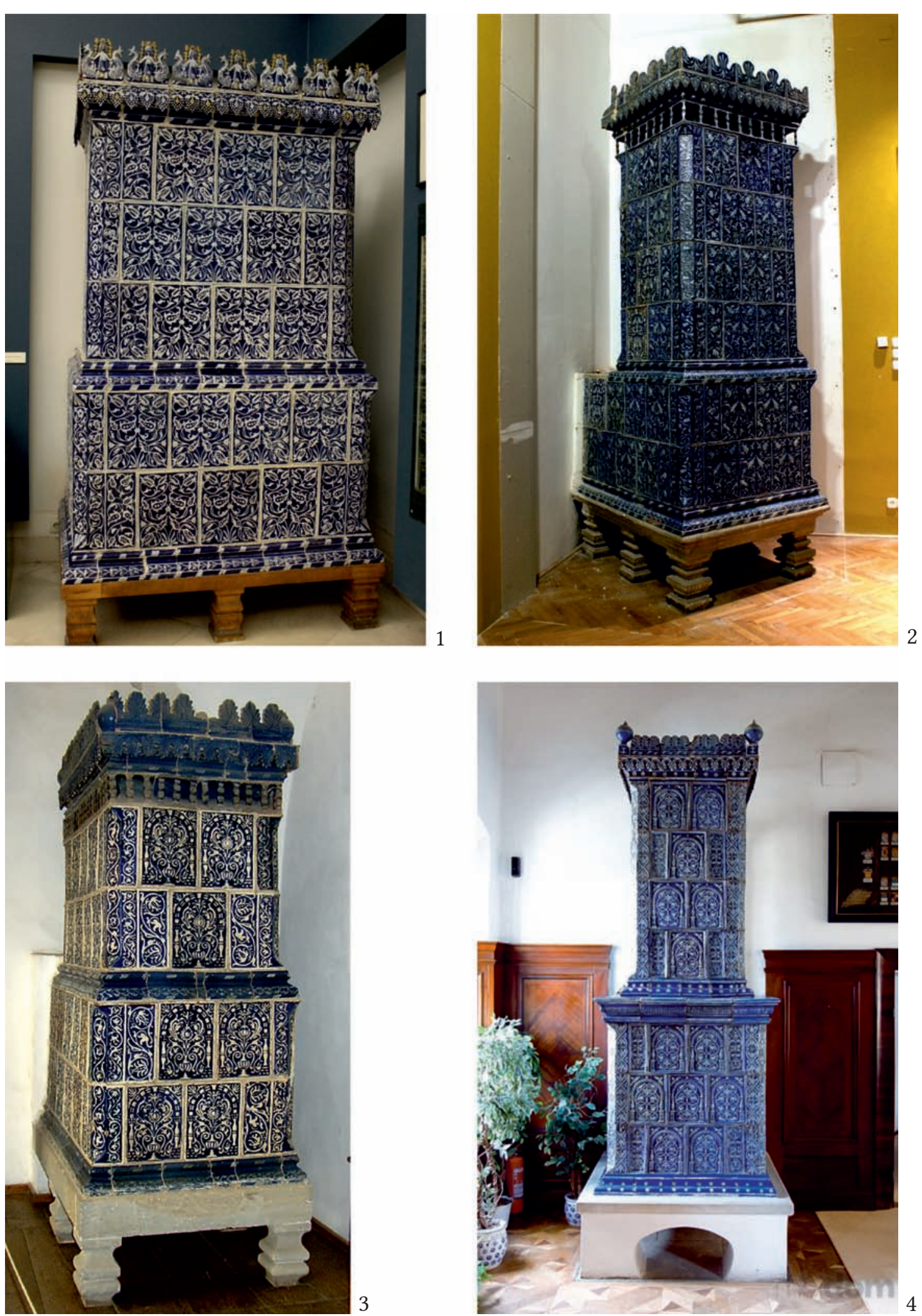

Abb. 1. 1 - Der Ofen von Trstené, heute im Ungarischen Nationalmuseum (Foto: R. Rakonczay), 2 - Der Ofen von Neusohl, heute im Kunstgewerbemuseum (Foto: D. Radványi), 3 - Der Ofen aus der Zipser Burg, heute auf der Burg Krásna Hôrka (Foto: Slowakisches Nationalmuseum - Museum Krásna Hôrka), 4 - Der Ofen aus Bibersburg, heute im Schloss Weinitz (Foto: Slowakisches Nationalmuseum - Museum Bojnice). 


\section{Forschungsüberblick}

Die Habaner, auch Wiedertäufer oder Anabaptisten genannt, sind Vertreter einer radikal-reformatorischen Bewegung, deren erste Gemeinden in der Schweiz entstanden. ${ }^{4}$ Im 16. Jahrhundert, nach der Niederlage im Deutschen Bauernkrieg (1525), wurden die Hutterer/Habaner in der Schweiz, in Deutschland und auch in Tirol verfolgt. ${ }^{5}$ Als die Gegenreformation, der Katholizismus, nach der Schlacht am Weißen Berg siegte, waren die Gemeinden der Wiedertäufer gezwungen zu fliehen, und eine Gruppen siedelte sich in Schächtitz (Čachtice/Csejte) in Nordungarn an. Im Jahre 1621 wurden sie von Gábor Bethlen aber in die Umgebung von Unterwinz (Vinț/Alvinc) und Großwardein (Oradea/Nagyvárad) in Siebenbürgen umgesiedelt. ${ }^{6}$ Eine Gemeinde von Anabaptisten gab es sowohl in Sárospatak ${ }^{7}$ als auch in Eger. ${ }^{8}$

Die obgenannten Öfen spielten bislang in der ungarischen Forschung keine bedeutende Rolle, obwohl ein vollständig erhaltener Ofen eine Besonderheit darstellt. Erstmals wurden sie 1929 von Kornél Divald erwähnt. ${ }^{9}$ Pál Voit und Imre Holl versuchten in „Alte ungarische Ofenkacheln " die Öfen von Neusohl und Trstené mit kunsthistorischen Methoden zu analysieren. ${ }^{10}$ Heřman Landsfeld rechnete den Habanern drei Öfen zu: den Ofen von Bibersburg, von Neusohl und von der Zipser Burg. ${ }^{11}$ Imre Katona beschäftigte sich zwar mit den Kacheln der Anabaptisten, mit den Öfen aber nur am Rande. ${ }^{12}$ Für die neueren Forschungen der letzten zehn Jahre stehen die kunsthistorischen Arbeiten von László Réti, ${ }^{13}$ Diána Radványi ${ }^{14}$ und Anna Ridovics. ${ }^{15}$

\section{Die Ofenkachel-Typen der Burg Čabrad'}

Acht Typen von Ofenkacheln in der Burg Čabrad' gehören zu den weiß- und blauglasierten Fayenceofenkacheln, von denen es Parallelen zu noch existierenden Öfen gibt. Der Ton der Kacheln wurde rot gebrannt und mit Sand gemagert. Sie haben eine hohe Qualität. Zu der verzierten, nur 0,9-1,1 cm dicken Vorderseite wurde die Rückseite aus Streifen geschnitten. Das Ende der Rumpfkonstruktion wurde mit einem kreisförmig durchgeschnittenen Rand gestaltet. Die Tiefe der Zarge beträgt nur 5-6 cm. Ein Textilabdruck ist auf der Rückseite nicht festzustellen.

Typ 1/1 $(\mathrm{M}=24 \times 30 \mathrm{~cm} ; \mathrm{S}=176) .{ }^{16}$ Auf der rechteckigen Kachel sind ein 0,5 cm breiter Stabrahmen und eine spiegelgleiche, detailreiche Komposition zu sehen, die einem umgekehrten Rankenherz ähnelt, aus dem weitere Blumenmotive auswachsen. Das Relief besteht aus zierlichen und büschelartigen Linien. Der Hintergrund ist blauglasiert, während die Motive mit weißen Glasur gemalt wurden. Der Typ kommt nur in diesen Farben vor (Abb. 13-14).

4 Katona 1976, 10.

5 Katona 1983, 12-13.

6 Katona 1983, 15; Krisztinkovich 1962, 10; Ringer 2014, 105.

7 Katona 1983, 18; Ringer 2014, 106.

8 Katona 1975, 127.

9 Divald 1929, 157.

10 VoIT - Holl 1954, 57.

11 LANDSFELD 1970, 23.

12 Katona 1983, 58; 191-193.

13 RADVÁNYI - RÉTI 2011.

14 RADVÁNYi 2013.

15 Ridovics et al. 2015; Ridovics et al. 2017.

16 Die Abkürzungen: Messung= Breite $\times$ Lange; Stückzahl. 


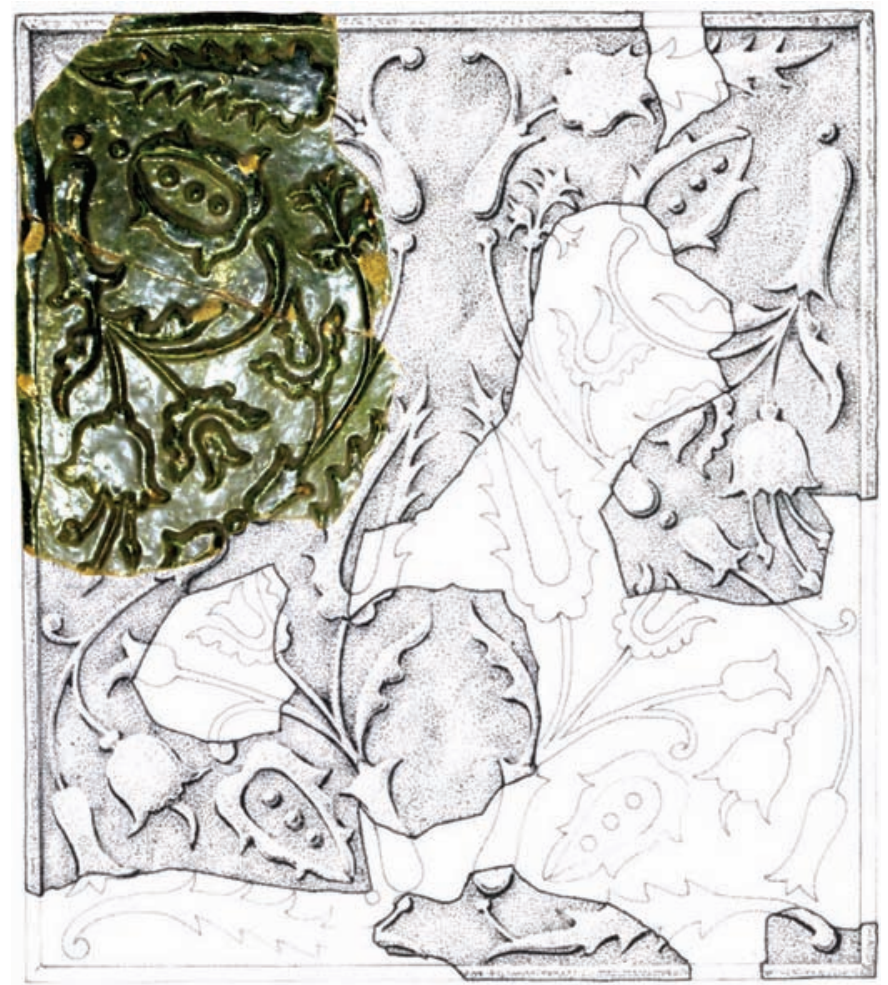

$A b b$. 2. Ofenkachel aus der Burg Diósgyőr (Nach: Boldizsár et al. 2010; Foto: R. Rakonczay).
Eine analoge Kachel gibt es von der Burg Diósgyőr, aber dieses Exemplar wurde aus weißem Ton mit grüner Glasur hergestellt ${ }^{17}$ ( $\left.A b b .2\right)$. Die Darstellungen der beiden Kacheln sind sehr ähnlich, aber sie wurden vermutlich nicht aus demselben Modell gestaltet.

Typ 1/2 $(\mathrm{M}=25 \times 30 \mathrm{~cm} ; \mathrm{S}=24) . \mathrm{Zu}$ dem Typ $1 / 1$ gehört eine abgeschrägte Eckkachel, die aus einer mit Pflanzenmotiven verzierten Halbkachel und aus einem abgeschrägten Eckteil besteht. Die Halbkachel wurde durch ein Stabrelief vom Eckelement getrennt. Die Ecke verfügt über drei Seiten, an denen symmetrische, S-förmige Pflanzenkompositionen zu sehen sind. Auf dem blauglasierten Hintergrund erscheinen die Motive mit weißer Glasur ( $A b b$. 15-16). Die genaue Analogie ist noch nicht bekannt.

Typ $1 / 3(M=22 / 24 \times 33 / 35 \mathrm{~cm} ; \mathrm{S}=21)$. Anhand der Scherben ist eine rechteckige Ofenkachel zu rekonstruieren, aber deren genaue Größe ist nur zu vermuten. Die Rekonstruktion wurde durch Vergleiche hergestellt. Auf der Kachel ist ein 0,5 cm breiter Stabrahmen und ein spiegelgleiches, dreimal sich umdrehendes Rankenmotiv zu sehen. Die Komposition besteht auch aus detailreichem und büschelartigem Relief. Der Hintergrund ist weißglasiert und die Motive treten mit blauer Glasur auf (Abb. 17).

Eine analoge Kachel ist auf dem Ofen von Neusohl zu sehen, aber diese Kachel erscheint mit blauen Hintergrund und weißen Motiven. ${ }^{18}$ Im Kunstgewerbemuseum in Budapest gibt es ein ähnliches Exemplar, aber dessen Fundstelle ist nicht bekannt ${ }^{19}$ (Abb. 3.1). Das gleiche Motiv kommt in der Burg Diósgyőr vor, aber die Kachel wurde aus weißem Ton hergestellt und grün glasiert $^{20}$ (Abb. 3.2). Die Frage, ob diese Analogien aus gleichen Modell hergestellt wurden, konnte man nicht untersuchen, weil die Kacheln sehr bruchstückhaft sind.

Der Typ 1/4 $(M=26 \times 32$ ? cm; $S=51)$. Die Kachel stellt eine sich mehrfach umdrehende Pflanzenkomposition dar, wie auf dem Typ $1 / 3$ zu sehen ist, aber die Ranken sind weniger detailreich und mehr stilisiert. Diesen Typ konnte die Verfasserin anhand der vorhandenen Fragmente nicht völlig ergänzen und rekonstruieren, weshalb die Lange der Kachel nicht genau bekannt ist. Diese Blattkachel kommt als einzige in beiden Variationen - sowohl mit blauem, als auch mit weißem Hintergrund vor -; deswegen ragt sie aus den Typen 1/1 und 1/3 hervor

17 BoldizsÁr et al. 2010, 82.

18 Inv.: 6542. KATONA 1983, 192.

19 Inv.: 53.5086.

20 Boldizsár et al. 2010, 81. 


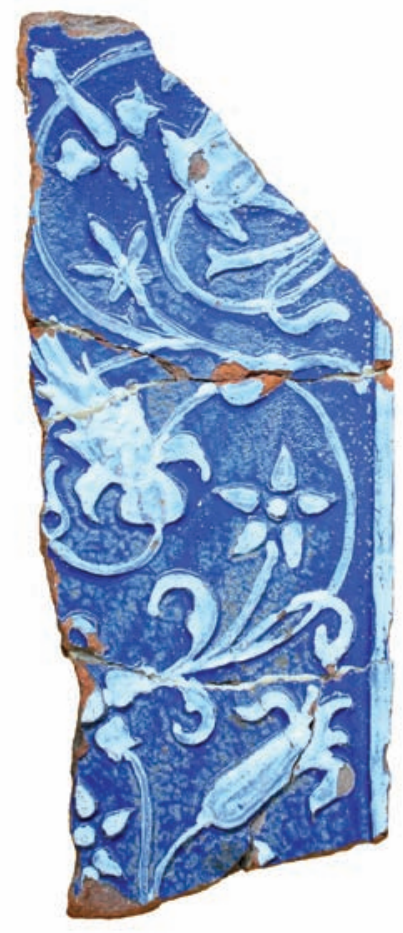

1

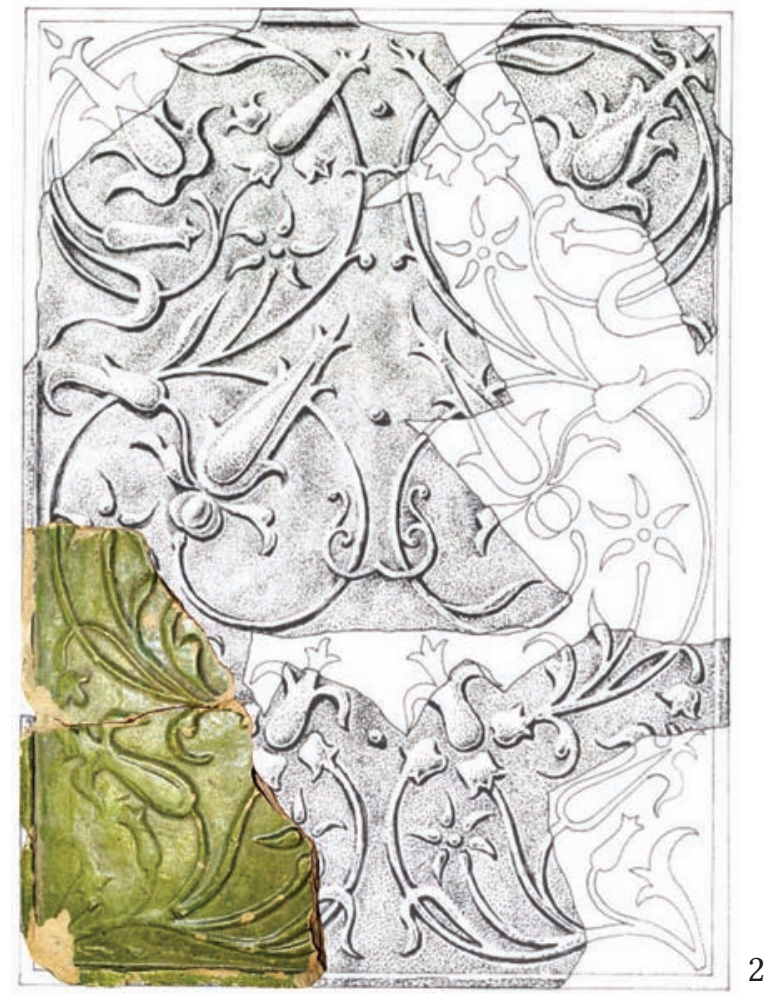

Abb. 3. 1 - Ofenkachel in der Sammlung des Kunstgewerbemuseums. Inv.: 53.5086 (Foto: R. Rakonczay), 2 - Ofenkachel aus der Burg Diósgyőr (Nach: Boldizsár et al. 2010; Foto: R. Rakonczay).

(Abb. 18-19). Auf der Rumpfkonstruktion ist in mehreren Fällen ein Durchstich festzustellen bzw. die Zargen wurden gelocht. Manchmal erscheinen zwei Löcher auf der Langseite. Da die Glasuren durch die Löcher auf die Rückseite des Kachelblattes geflossen sind, wurden die Zargen vermutlich vor dem Glasieren perforiert, und die Löcher wurden vor der Verbrennung wieder mit Ton verschlossen. Die genaue Analogie ist noch nicht bekannt.

Der Typ 1/5 (M=22×20? cm; S= 31). Die Kranzkacheln bilden ein sich wiederholendes Muster: Sie wurden unten gewinkelt und oben wellig gestaltet, und darauf ist ein Schleifbandstrauß zu sehen. Dieser Typ kommt in der Burg Čabrad' sowohl mit blauem als auch mit weißem Hintergrund vor (Abb.20).

Ein analoges Beispiel bietet der Ofen von Neusohl. Im Kunstgewerbemuseum werden einige ähnliche Scherben aufbewahrt, jedoch ist deren Herkunftsort nicht bekannt. ${ }^{21}$ Auch aus Schloss Lukáčovce (Lakács), das in der Nähe der Burg Čabrad’ liegt, ist ein ähnliches Exemplar bekannt. ${ }^{22}$ In der Burg Eger erscheinen Kacheln mit polychromer Glasur. ${ }^{23}$ In Sárospatak wurde auch eine analoge Kachel mit gelbgrünen Hintergrund und blauen Motiven gefunden. ${ }^{24}$ Auch in Siebenbürgen tritt dieser Typ auf. Im Schloss Radák-Pekri in Thürendorf (Ozd/Magyarózd) gibt es ähnliche Ofenkacheln aus rot gebranntem Ton und mit grüner Glasur ${ }^{25}$ (Abb. 4). Diese Kacheln wurden aber aus verschiedenen Modellen, sog. Matrizen, hergestellt. Zu diesem

21 Unpubliziert. Herzlichen Dank Diána Radványi für die Information!

22 ČUrný 2004, Taf. 55. 12_004

23 Unpubliziert. Burg Eger, 2017. Ausgrabungsleiter: Gergely Buzás. Herzlichen Dank Gergely Buzás, Edit Kocsis und Melinda Síkéné Kovács für die Informationen!

24 Gyuricza 1992, Kat. 298.

25 KÉMENES 2002. 


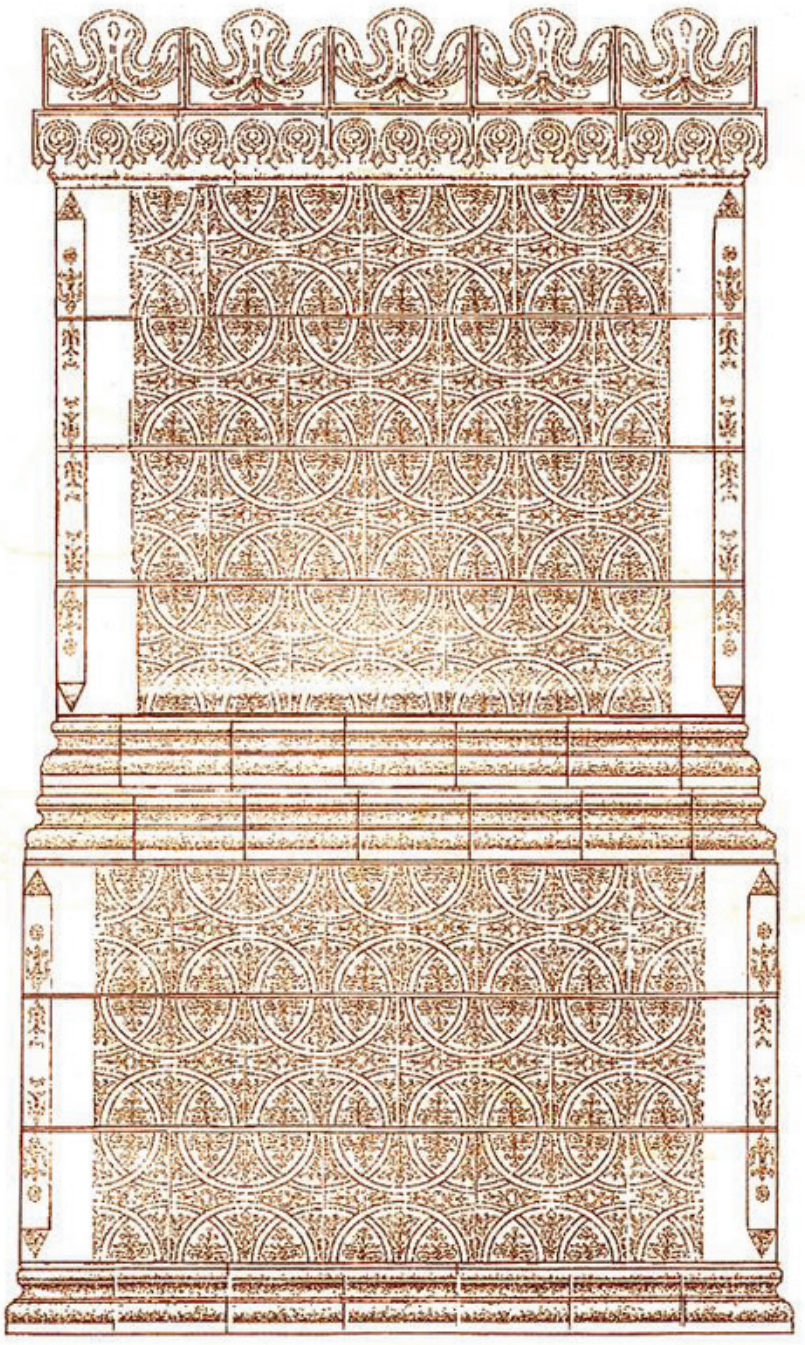

$A b b$. 4. Ofenrekonstruktion aus dem Schloss RadákPekri, in Thürendorf (KÉMENES 2002).

Analogien mit einer polychromen Glasur bekannt ${ }^{29}(A b b .8,10)$. Die vergleichbaren Kacheln wurden aber aus verschiedenen Modellen hergestellt.

Der Typ 1/7 $(\mathrm{M}=21 \times$ ? $\mathrm{cm} ; \mathrm{S}=3)$. Da die gefundenen Fragmente sehr bruchstückhaft sind, ließen sich die genaue Größe und der Abschluss der Kranzkachel nicht vollkommen rekonstruieren. Die Kachel besteht aus drei Elementen, wie der Typ 1/6, und zeigt ein sich wiederholendes Muster. Die Blumen werden durch die halbkreisförmigen Ranken gestaltet. Dieser Typ ist nur mit blauem Hintergrund und mit weißer Verzierung aus Čabrad' bekannt (Abb. 22).

Genaue gleiche Kacheln sind aus den „Habaner“- bzw. Fayenceöfen bekannt. Sie erscheinen sowohl auf dem blau- und weißglasierten Ofen im Schloss Weinitz ${ }^{30}$ als auch auf

26 Нupко 2013, 70.

27 DÖRY 2005, 195.

28 HOMOLA - TOMOČEK 2017, 28.

29 Unpubliziert. Burg Eger, 2017. Ausgrabungsleiter: Gergely Buzás. Herzlichen Dank Gergely Buzás, Edit Kocsis und Melinda Síkéné Kovács für die Informationen!

30 Hupко 2013, 75.

Kranzkacheltyp gehören auch formale $\mathrm{Pa}$ rallelen. Ein Abschluss des grünglasierten Ofens von Bibersburg ist ebenfalls ähnlich, dort ist aber auf der Kachel eine Rose $\mathrm{zu}$ sehen $^{26}$ (Abb. 5-6). Eine Ofenkachel mit ähnlichen Formen, aber abweichender Verzierung, ist bei der Ausgrabung der Habanerwerkstatt von Kesselsdorf (Košolná/Gósfalva) zum Vorschein gekommen $^{27}$ (Abb. 7).

Der Typ 1/6 $(\mathrm{M}=21 \times 10,5 \mathrm{~cm} ; \mathrm{S}=19)$. Die Kranzkachel besteht aus drei herabhängenden Weintrauben, die eine wellig gemalte Platte verbindet. Auf den Trauben sind Ranken und Blätter zu sehen. Der Typ kommt in beiden Varianten - sowohl mit blauem Hintergrund als auch mit weißem Hintergrund - vor (Abb.21).

Genaue Vergleichsbeispiele liefern die Öfen von Neusohl und von Trstené. Diese Ofenkacheln stammen aber nicht aus dem gleichen Modell, obwohl ein gemeinsames Vorbild nachgewiesen ist. Neben den komplett erhaltenen Öfen wurde dieser Kacheltyp auch in der Ausstellung auf der Burg Slowakisch-Liptsch (Slovenská L’upča/ Zólyomlipcse) präsentiert $^{28}(A b b$. 9). In der Burg Eger sind ${ }^{29}$ (Abb. 8, 10). Die vergleichbaren Kacheln

.


den grünglasierten Heizanlagen von $\mathrm{Bi}$ bersburg $^{31}$ (Abb. 5-6), im Schloss Lukáčovce, ${ }^{32}$ auf dem Ofen in der Burg Krásna Hôr$\mathrm{ka}^{33}$ sowie auf der Burg Füzér ${ }^{34}$ und im Schloss von Thürendorf. ${ }^{35}$

Der Typ $1 / 8(\mathrm{M}=23,5 \times 14 \mathrm{~cm} ; \mathrm{S}=62)$. Die Gesimskachel besteht aus einem kleineren und einem größeren Rundstab. Auf der Gesimskachel ist kein Relief zu sehen; sie wurde mit gemalten Motiven verziert. Auf den Ofenkacheln mit blauem Hintergrund wurde mit weißer Farbe gemalt, und auf dem weißen Hintergrund wurden blaue Motive aufgebracht, unten eine Reihe mit Herzen, oben kleine Schraffierungen (Abb. 23).

Analogien sind aus den Öfen von Trstené, Neusohl und Krásna Hôrka bekannt, aber auf diesen Gesimskacheln gibt es keine Schraffierungen wie bei dem Čabrad’er Typ. Diese Verzierung ist nur auf den Kacheln von Slowakisch Liptsch zu sehen. ${ }^{36}$ In der Burg Eger erscheinen mit gemalter Herzreihe verzierte Gesimskacheln ohne Schraffierung, allerdings mit einem gemalten Dachziegelmotiv. ${ }^{37}$ Die Herzreihe tritt auf einem Teller aus der Habanerwerkstatt in Sárospatak auf ${ }^{38}$ (Abb. 11).

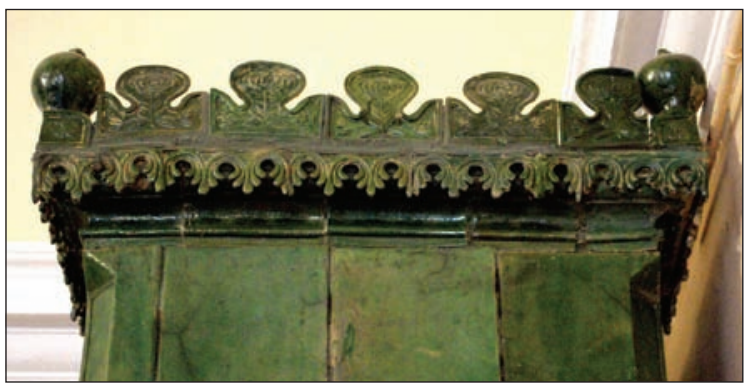

$A b b$. 6. Die Kranzkacheln des grünglasierten Ofens von Bibersburg (Foto: R. Rakonczay).

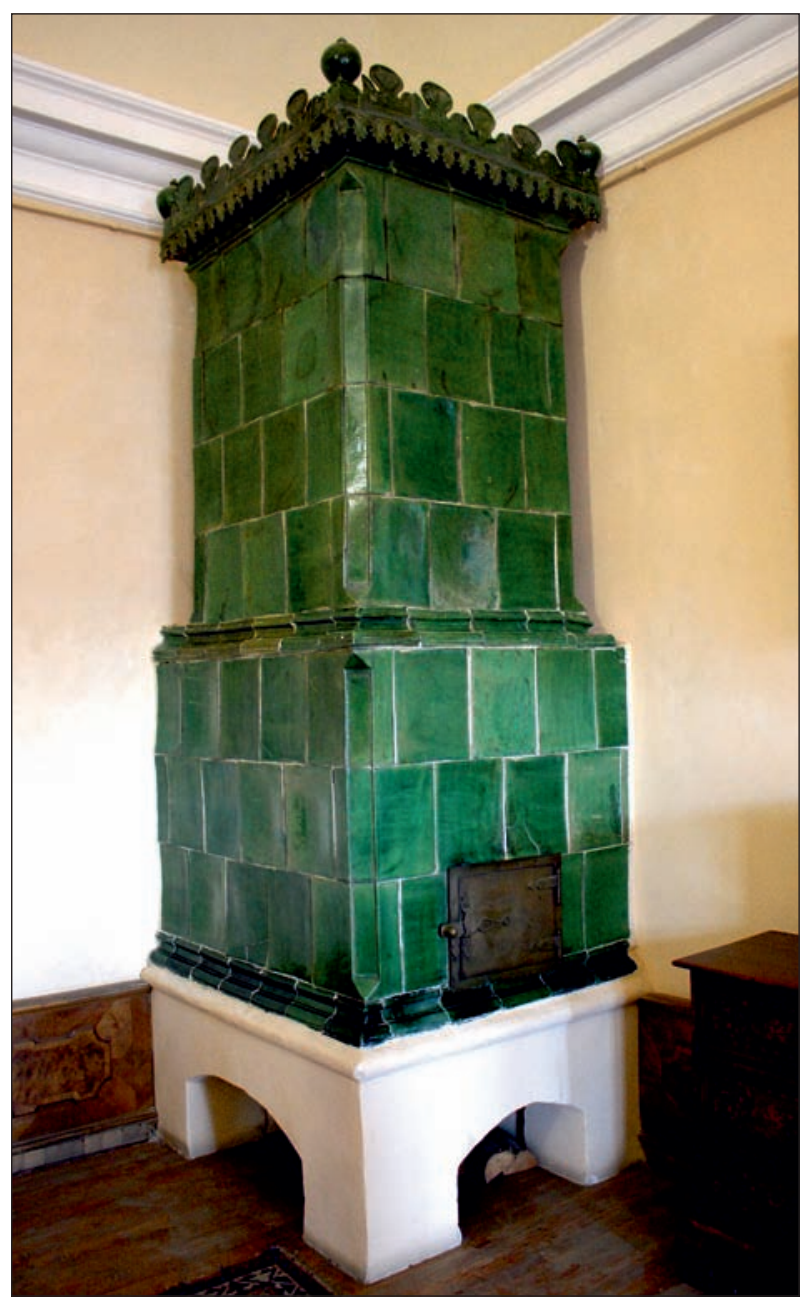

Abb. 5. Grünglasierter Ofen auf der Bibersburg (Foto: R. Rakonczay).

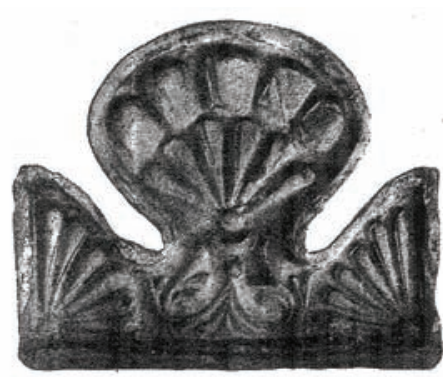

$A b b$. 7. Kranzkachel aus der Habanerwerkstatt Kesselsdorf (Döry 2005, 195, Abb. 5).

31 Döry 2005, 192, Abb. 3.

32 ČUrnÝ 2004, Taf. 55. 13003

33 Radványi 2013, 60.

34 Gyuricza 1992, 106, Abb. 97; Simon 2000, Taf. 30. Abb. 2.

35 KÉMENES 2002.

36 Homola - ToMočEK 2017, 28.

37 Unpubliziert. Burg Eger, 2017. Ausgrabungsleiter: Gergely Buzás. Herzlichen Dank Gergely Buzás, Edit Kocsis und Melinda Síkéné Kovács für die Informationen!

38 Ringer 2014, Taf. 139. 


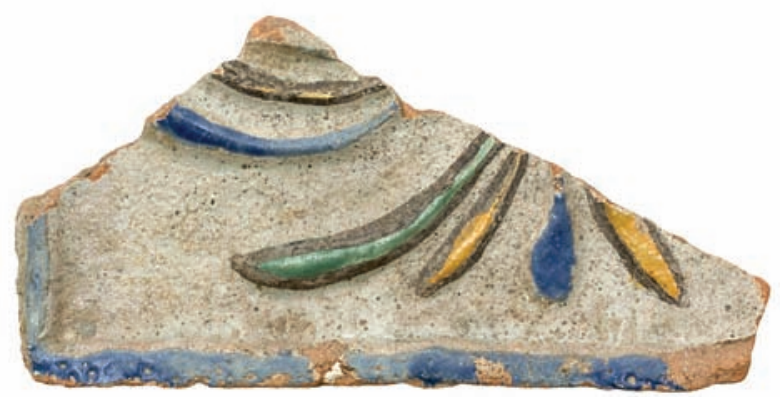

Abb. 8. Kranzkachel aus der Burg Eger (Foto: M. Síkéné Kovács).

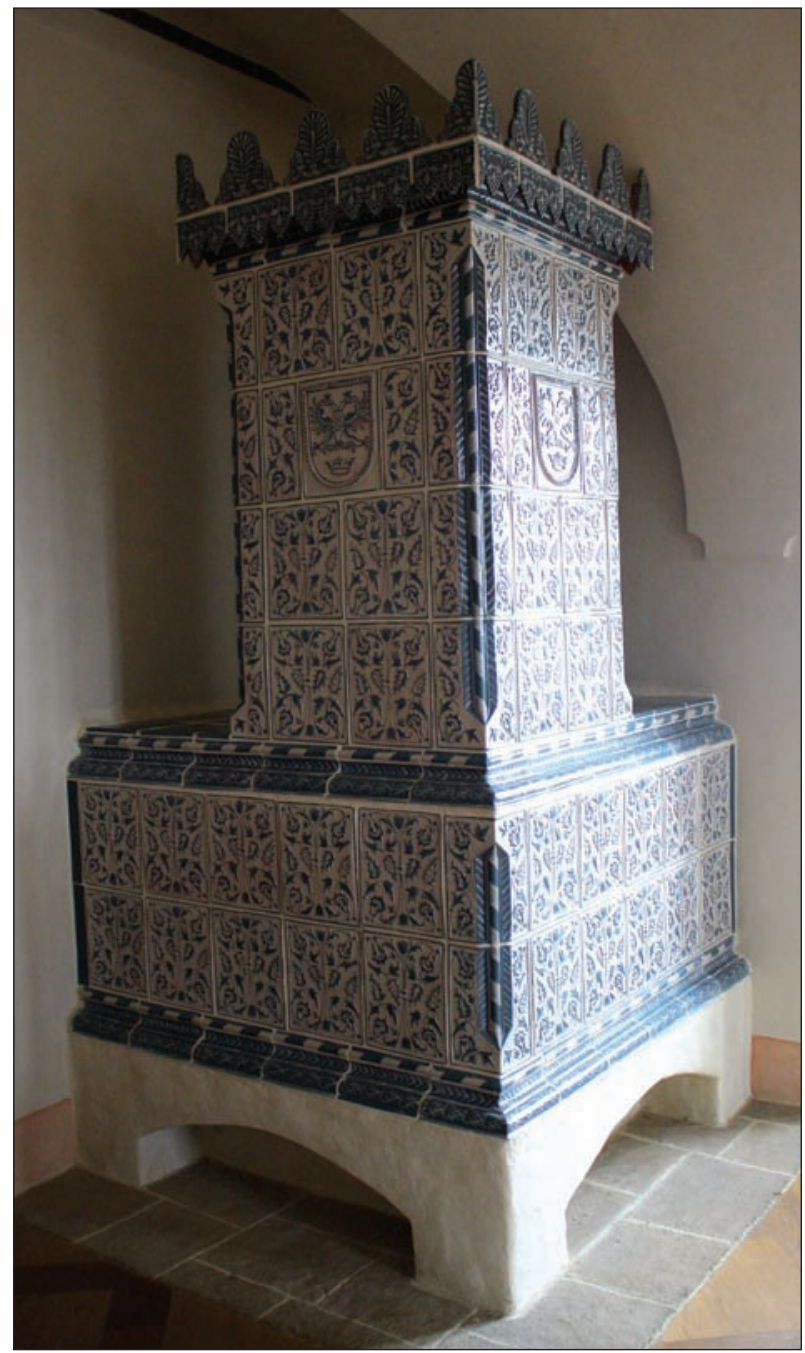

Abb. 9. Ofenrekonstruktion auf der Burg Slowakisch Liptsch (Foto: R. Rakonczay).

\section{Die grünglasierte Gruppe}

Die Fayencetypen werden durch eine grünglasierte Gruppe ergänzt, deren Motive auf die erwähnten Öfen und Ofenkacheltypen hindeuten, deren Verzierungen aber bereits vereinfacht wurden. Die Herstellungsart - der Ton und die Rumpfkonstruktion - ähnelt der blau- und weißglasierten Gruppe. Die Ofenkacheln sind mit weißem Tonschlicker engobiert und grünglasiert. Auf der Vorderseite der Blattkacheln tritt manchmal sekundär weißen Kalkflecken auf, der darauf hinweist, dass die Kacheln verbessert wurden.

Der Typ 2/1 $(\mathrm{M}=20 \times 25 \mathrm{~cm} ; \mathrm{S}=28)$. Auf der rechteckigen Ofenkachel ist Komposition ähnlich wie die auf dem Typ 1/1, aber weniger detailreich und einfacher. Die Ranken und die Blumen sind dicker, nicht so zierlich und weniger herausragend. Die Komposition wird von einen $0,5 \mathrm{~cm}$ breiten Stabrahmen umringt. Hellgrünglasiert, engobiert (Abb. 24-25) Eine genaue Analogie ist noch nicht bekannt.

Der Typ $2 / 2(M=20 \times 25 \mathrm{~cm} ; \mathrm{db}=7)$. Zum Typ 2/1 gehört eine abgeschrägte Eckkachel. Die Konstruktion und die Verzierung der Eckkachel ähneln dem Typ 1/2, aber vereinfacht. Der Abschluss der Schräge der Eckkacheln wurde in der obersten und untersten Reihe dreiecksförmig gestaltet. In diesem Fall kommt keine Eckkachel mit einem dreiecksförmig gestalteten Abschluss vor, aber es gab vermutlich. Die Kacheln wurden engobiert und grünglasiert ( $A b b$. 26). Genaue Vergleiche sind noch nicht bekannt, aber die Motive lassen sich auf die „Habaner“-Öfen zurückführen.

Der Typ 2/3 $(M=20 \times 25 \mathrm{~cm} ; \mathrm{S}=34)$. Die rechteckige Ofenkachel wurde anhand der vorhandenen Scherben nur teilwesie ergänzt und rekonstruiert. Auf der Tafelkachel ist ein spiegelgleiches, dreimal sich wiederholendes Rankenmotiv - wie auf dem Typ 1/3 - zu sehen. Das weniger bildhafte und detailreiche Muster wurde engobiert und grünglasiert. Die Glasur ist dunkler als auf den Typen 2/1 und 2/2 und mehrmals abgeblättert ( $A b b$. 27). Ein ähnliches Beispiel ist nicht bekannt. 
Der Typ $2 / 4(M=20 \times 25 \mathrm{~cm} ; \mathrm{S}=12)$. Eine abgeschrägte Eckkachel, die aus einer Halbkachel vom Typ 2/3 und aus einem Eckelement besteht. Der Eckteil gliedert sich in drei Seiten, auf dem S-förmige Rankenmotive zu sehen sind. In vorliegenden Fall handelt es sich um Scherben mit dreiecksförmigen Abschluss, die in der untersten und obersten Reihe des Ofens eingebaut wurden. Die weniger aufwändige Verzierung wurde engobiert und grünglasiert (Abb. 28-29). Eine zu den Habaneröfen zählende Eckkachel aus der Burg Diósgyőr zeigt eine ähnliche Struktur und ähnliche Verzierungen. ${ }^{39}$

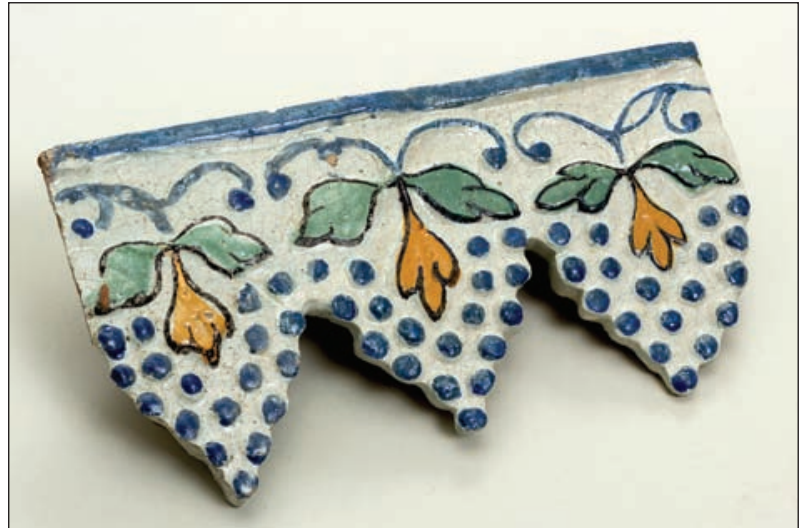

Abb. 10. Kranzkachel aus der Burg Eger (Foto: M. Síkéné Kovács).

Der Typ 2/5 $(M=14 \times 20 \mathrm{~cm} ; \mathrm{S}=8)$. In der Mitte der symmetrischen Kranzkachel ist eine Blume mit sechs Blütenblättern zu sehen. Die Blume wurde durch kreis- und herzförmige Rankenmotive umrahmt. Der Abschluss der Kachel ist anhand der Scherben nicht völlig rekonstruierbar; deswegen ist die Ergänzung fraglich. Die Kachel wurde engobiert und grünglasiert (Abb. 30). In einigen Fällen wurde der Ton mit Hilfe eines Tuches ins Modell gedrückt. Eine vergleichbare Kachel ist nicht bekannt.

Der Typ 2/6 $(M=8 \times 20 \mathrm{~cm} ; \mathrm{S}=5)$. Die Kranzkachel besteht aus drei Teilen, auf denen halbkreisförmig sich wiederholende Rankenmotive mit einem herzförmigen Abschluss zu sehen sind. Die Kachel wurde engobiert und grünglasiert ( $A b b$. 31). Auf zwei Scherben ist ein sichtbarer Textilabdruck festzustellen. Eine genaue Analogie ist bislang nicht bekannt.

\section{Die Imitation der Fayencekacheln}

$\mathrm{Zu}$ diesen Typen von Ofenkacheln gehört eine dritte Kachel-Gruppe mit blauen und weißen Farben - allerdings von nicht allzu hoher Qualität. Die Farben wurden nicht durch Glasieren erreicht, sondern die Ofenkacheln wurden mit weißer Tonschlicke engobiert und dann die Motive blauglasiert. Anschließend wurde die Vorderseite der Kachel mit einer durchsichtigen Glasur übergossen. Daher wirken die Glasuren verwischt, und die Umrisslinien der blauen Glasur sind unscharf.

Der Typ 3/1 $(\mathrm{M}=24 \times 29 \mathrm{~cm} ; \mathrm{S}=12)$. Auf der rechteckigen Ofenkachel ist eine mit Blumen, Beeren und Ranken detailreich ver-

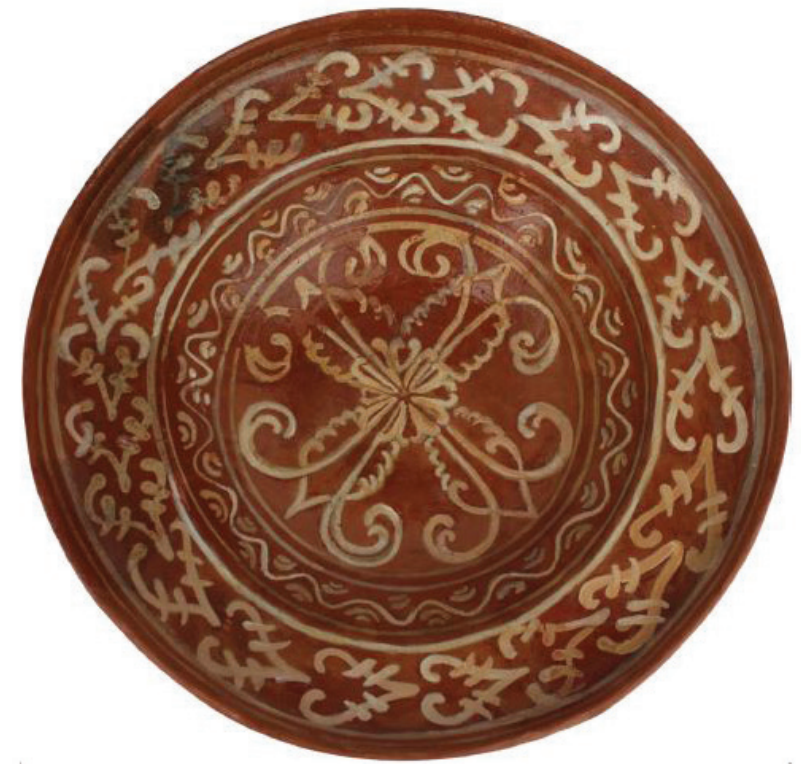

Abb. 11. Teller aus der Habanerwerkstatt von Sárospatak (RINGER 2014, Taf. 139). 
zierte Komposition zu sehen. Die Darstellung passt zu den spiegelgleichen Tafelkacheln - wie die Typen 1/1 und 1/3 -, der Ofenkacheltyp ist aber nicht genau spiegelgleich. Die Komposition wurde mit einem 0,5 cm breiten Stabrahmen umringt. Die blaue Glasur wirkt verlaufen. Die Rückseite der Kachel, die sog. Rumpfkonstruktion, weicht von den blau-weiß- und grünglasierten Gruppen ab. Die kürzere Zarge wurde als Streifen geschnitten und dann gedreht. Der Rand der Zargen wurde zweifach gegliedert. Die Tiefe der Ofenkacheln beträgt ca. $5 \mathrm{~cm}(A b b .32)$.

Eine ähnliche Kachel stammt von der Burg Slowakisch Liptsch, wo sie mit weißem Hintergrund und blauen Motiven - wie auch auf der Burg Čabrad' - vorkommt ${ }^{40}$ (Abb. 9). In der Burg Eger sind ebenfalls ähnliche, polychrom glasierte Ofenkacheln zum Vorschein gekommen ${ }^{41}$ (Abb. 12). Die Čabrader Ofenkacheln stammen aber aus einem anderen Modell. Da die Gestaltung der Verzierung - Ranken und Blumen den blau- und weißglasierten Typen ähnelt, aber die Herstellungsart der Oberfläche (Engobieren und Glasieren) der Kachel eine mindere Qualität haben (vermutlich eine Kostenfrage), kann vermutet werden, dass diese Ofenkacheln als Ersatzkacheln dienten oder sie auf einer nicht so gut sichtbaren Ofenseite eingebaut wurden.

Der Typ 3/2 (M= ?; $\mathrm{S}=3)$ Diesen Ofenkacheltyp konnte man anhand der gefundenen Scherben nicht rekonstruieren. Wegen der

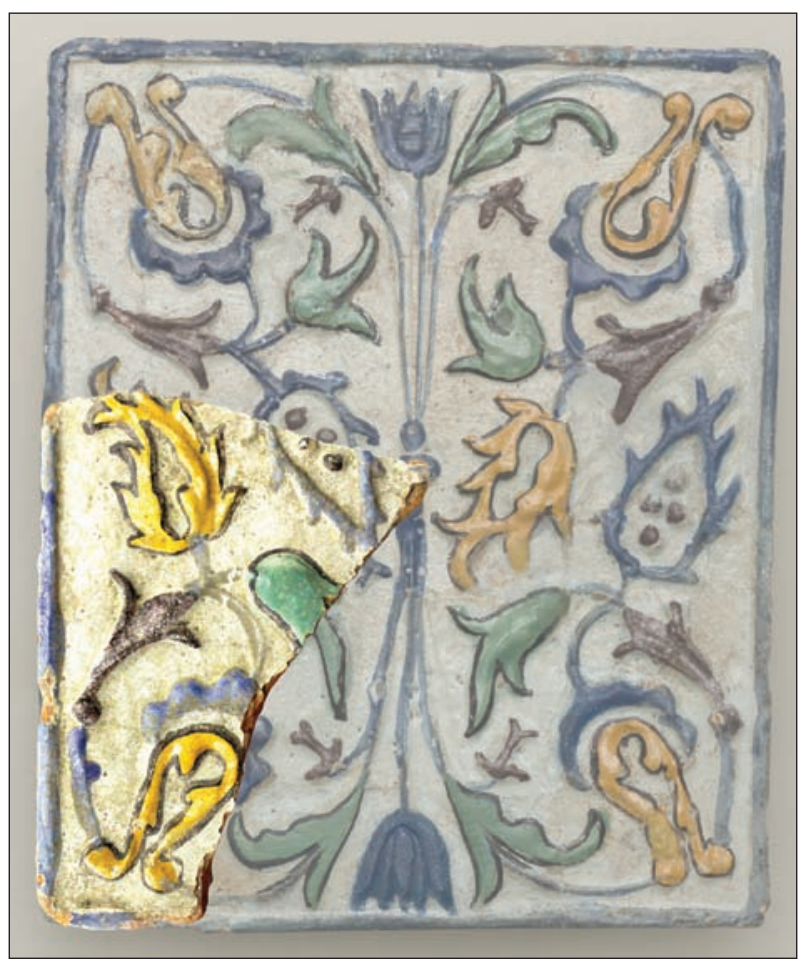

Abb. 12. Ofenkachel aus der Burg Eger (Foto: M. Síkéné Kovács und R. Rakonczay). Verzierung, der Engobe und Glasur und des Tons zählt sie zu dieser Gruppe. Die Scherben sind sehr bruchstückhaft, jedoch konnte ein Fragment als abgeschrägte Eckkachel identifiziert werden, auf der sich umdrehende Rankenmotive zu sehen sind. Die anderen zwei Scherben ähneln dem Typ 1/1. Die durchsichtige Glasur wurde etwas grünlich getönt, während die Konturen der blauen Glasur fast gänzlich verschwunden ist. Die dazu gehörende Rumpfkonstruktion konnte nicht mehr festgestellt werden (Abb. 33).

\section{Rekonstruktionsmöglichkeiten}

Die o.g. Ofenkacheltypen weisen mindestens auf vier Öfen oder Ofentypen hin. Aus den Fayencekacheltypen könnten zwei Öfen oder Ofentypen - ein Ofen mit blauem Hintergrund und eine weitere Heizanlage mit weißem Hintergrund - errichtet worden sein. Auch in der Gruppe mit grünglasierten Fayencekacheln kann man auf zwei Öfen schließen. Die Typen 3/1 und 3/2 sollten als Ersatzkacheln dienen; ihre Scherben sind sehr bruchstückhaft und kommen nur in geringer Menge vor.

40 Homola - Tомос̌Eк 2017, 28.

41 Unpubliziert. Burg Eger, 2017. Ausgrabungsleiter: Gergely Buzás. Herzlichen Dank Gergely Buzás, Edit Kocsis und Melinda Síkéné Kovács für die Informationen! 
Die Fayenceofenkacheln können auf einen blauen und einen weißen Ofen hindeuten. Deren Existenz wird durch die immer entweder mit blauen oder mit weißen Hintergrund vorhandenen Tafelkacheln und die in beiden Varianten (mit blauen und mit weißen Hintergrund) bekannten Gesims- und Kranzkacheln belegt ( $A b b$. 34-35). Auf zwei Öfen oder Ofentypen weisen auch die unterschiedlichen Größen der Typen 1/1 und 1/3 hin. Obwohl die genaue Größe des Typs 1/3 nicht genau bestimmt werden kann, weichen auf jeden Fall die Breiten der beiden Ofenkacheln voneinander ab. In der Burg Diósgyőr kommen die vergleichbaren Typen auch in anderen Größen vor. Die beiden Rekonstruktionsversuche orientieren sich an den Öfen von Neusohl und Trstené. Die Öfen hatten einen Prisma ähnlichen oberen und einen ebensolchen unteren Aufbau, der mit abgeschrägten Eckkacheln abgeschlossen wurde. Auf der Rekonstruktionzeichnung des weißen Ofens wurden die Eckkacheln als Leerflächen markiert, weil sie bisher noch unbekannt sind, aber ihr Vorhandensein vermutet werden kann. $\mathrm{Zu}$ den beiden Öfen hätten dieselben Gesims- und Kranzkacheln gehören können, weil sie in beiden Varianten, mit blauer und mit weißer Glasur, bekannt sind. Der Kranzkacheltyp 1/5 bildete die oberste Reihe der Öfen, während der Kranzkacheltyp 1/6 darunter angebracht war. Noch bleibt die Frage offen, wo der Kranzkacheltyp 1/7 verbaut war. Diese Kachel ist nur mit blauem Hintergrund und weißen Motiven bekannt, weshalb sie als eine herabhängende Kranzkachel auf dem blauen Ofen gedient haben könnte. Da von diesem Typ nur einige Scherben vorkommen, könnte die Kranzkachel auch zu einem anderen, bisher unbekannten Ofen gehören. Vom Typ 1/1 gibt es die größte Menge an Scherben, daher kann man mit mehreren blauen Öfen rechnen. Der Typ 1/4 ist ebenfalls fraglich. Aufgrund der vorgefundenen Menge der Kacheln bildeten sie vermutlich einen anderen, selbstständigen Ofen. Da die Ofenkacheln in beiden Varianten, sowohl mit blauem als auch mit weißem Hintergrund, vorkommen, kann man einen weiteren Ofen annehmen, der aus dem Kacheltyp 1/4 und aus den schon bekannten Gesims- und Kranzkacheln bestanden haben könnte. Man kann sich aber auch vorstellen, dass dieser Ofenkacheltyp als Ersatzkacheln auf weißen und blauen Öfen diente, die später in Öfen eingebaut wurden - wie die architektonischen Tafelkacheln auf den Öfen von Neusohl und von Krásna Hôrka. ${ }^{42}$

Diese beiden Ofentypen - der weiße und der blaue - kommen auch in den Schriftquellen vor. Aufgrund der Inventare der Familie Batthyányi ist festzustellen, dass die weißen Öfen sich meistens in der Stube der Dame des Hauses befanden, während die blauglasierten Öfen in der Stube des Herrn oder in den Repräsentationsräumen der Burg oder des Schlosses standen. ${ }^{43}$ Die weißen Öfen erscheinen nicht so häufig in den Inventaren - und auch bei Ausgrabungen kommen nicht so viele Ofenkacheln mit weißem Hintergrund aus dieser Zeit zutage. Bisher ist ein ähnlicher, komplett erhaltener weißer Ofen deshalb auch nicht bekannt. Diese Fayencetechnik mit weißer Glasur war hochpreisig und daher selten. ${ }^{44}$ In der Burg Čabrad gibt es ebenfalls nur wenige weißglasierte Ofenkacheln.

Auch in der Gruppe der grünglasierten Kacheln werden zwei Öfen oder Ofentypen vermutet, die mit ähnlichen Gesims- und Kranzkacheln hergestellt wurden. Aufgrund der Abweichungen der Typen 2/1 und 2/3 - ihrer unterschiedlichen Verzierung und Glasur - werden die zwei Ofentypen gesondert betrachtet (Abb. 36-37). Die beiden Öfen hatten in diesem Fall 
einen prismatischen oberen und einen ebensolchen unteren Aufbau, den abgeschrägte Eckkacheln abschlossen. Der Kranzkacheltyp 2/5 bildete die oberste Kachelreihe, während die dreiteilige Kranzkachel darunter angebracht gewesen sein könnte. In dieser Gruppe gibt es keine Gesimskachel, doch sind auf der Burg Čabrad' viele grünglasierte Gesimskacheln ohne Relief zum Vorschein gekommen, deren Gestalt dem Gesimstyp 1/8 ähnelt. Daher können wir vermuten, dass zu diesen Öfen eine relieflos grünglasierte Gesimskachel gehörte. Auf den Fayenceöfen ist eine gemalte Gesimskachel ohne Relief zu sehen, die darauf hindeutet, dass zu den grünglasierten Heizanlagen die schmucklosen Gesimskacheln gehörten.

Bei den beiden Ofentypen in der dritten Gruppe ist es fraglich, ob sie zusammen gehören. Zum einen kommen die Ofenkacheln nur sehr bruchstückhaft vor, weswegen die Untersuchungen erschwert sind. Andererseits fehlen ähnliche, parallele Motive auf den Ofenkacheltypen 3/1 und 3/2; in dieser Art sind sie also nicht demselben Ofen zuzuordnen. Die weiße Engobe mit blauer und durchsichtiger Glasur ist aber ganz gleichartig. Da aus diesem Kacheltyp 3/2 nur einige Scherben vorkommen, dienten sie vermutlich als Ergänzungskacheln auf den früh eren Fayenceöfen - darauf deuten die ähnlichen Motive hin. Diese Tafelkacheln wurden aber einfacher und ohne richtige Fayencetechnik gefertigt, was darauf hinweist, dass sie auf der Burg oder in der Nachbarschaft hergestellt und als billigere Ersatzkacheln nach Originalstücken gefertigt wurden.

\section{Die Datierung und die Frage der Werkstätte}

Die vorgestellten Ofenkacheln weisen auf komplett erhaltene Fayenceöfen hin. Sowohl die ähnlichen Motive, dieselben Gesims- und Kranzkacheln und die gleichartigen Tafelkacheln, als auch die erscheinende Fayencetechnik und die Gestaltung beweisen die Verbindung zwischen den Öfen und den vorkommenden Ofenkacheln. Obwohl die Herstellungsart der Ofenkacheln an noch bestehenden Öfen kaum zu untersuchen ist, weil sie fest an den Öfen verbaut sind, konnte festgestellt werden, dass sowohl die Ofenkacheln als auch die Čabrader Typen aus rot gebranntem Ton hergestellt wurden. ${ }^{45}$

Die Ursprünge der erhaltenen Öfen ist noch nicht hinreichend erforscht, doch wurden sie sicherlich in einer Habanerwerkstatt hergestellt. ${ }^{46}$ Im heutigen Ungarn ist nur eine einzige Habanerwerkstatt in Sárospatak belegt, ${ }^{47}$ deren Ofenkachelmaterial im Vergleich zu den „Habaner"-Öfen eine wichtige Rolle spielt. Aus den Schriftquellen sind auch Habanertöpfer in Siebenbürgen bekannt; daher könnten siebenbürgische Befunde bei der Erforschung hilfreich sein. Überdies dienen die Ofenkacheln aus den in Mähren entdeckten Habanerwerkstätten als Anhaltspunkt.

Auf Grund der bisherigen Forschungen zeigen die noch erhaltenen Öfen und die Čabrader Kacheln weder Parallelen mit Ofenkacheln aus Sárospatak noch mit dem Fundmaterial der mährischen Habanerwerkstätte oder mit siebenbürgischen Exemplaren. Nur einige Kachelmotive treten sowohl bei Funden aus Sárospatak als auch in Siebenbürgen auf, z. B. die Herzreihe, die auf der Gesimskachel und auf einem Teller aus Sárospatak vorhanden ist, ${ }^{48}$ und die spiegel-

45 Herzlichen Dank Diána Radványi für die Information!

46 RADVÁNyi 2013, 57.

47 RINGER 2014.

48 RiNgER 2014, Taf. 139. 
gleichen Pflanzenmotive im nischenartigen architektonischen Rahmen, die auf den Öfen von Neusohl, von Krásna Hôrka und von Weinitz und auch in Sárospatak auftreten. ${ }^{49}$ Auf der Burg Čabrad' sind sie aber nicht bekannt. Eine ähnliche Ofenkachel wurde in Altenmarkt (Stará Břeclav) in Mähren gefunden. ${ }^{50}$ Der Ofen von Bibersburg wurde von Ludwig Döry und Daniel Hupko als Produkt der Habanerwerkstatt Kesselsdorf identifiziert ${ }^{51}$ deren Ofenkacheln aber nicht als eindeutige Parallelen zu den Öfen von Neusohl und Trstené oder zu Čabrad’er Typen dienen können. Auf dem Fayenceofen von Bibersburg tauchen die schon bekannten Gesimsund Kranzkacheln nicht auf, und die Tafelkacheln weichen ebenfalls davon ab.

Im Kreis der mährischen Ofenkunst der Habaner sind diese Motive kaum bekannt. Die mährischen Forscher ordnen den Anabaptisten drei Darstellungen zu: die Rapportmuster mit Halbkreisen oder mit Herzen und die Medaillonkacheln. ${ }^{52}$ Der Typ 1/5 ist der einzige, dessen Form auch in der Werkstatt von Kesselsdorf auftritt, aber seine Verzierung unterscheidet sich vom Čabrad’er Exemplar. ${ }^{53}$ Analogien dieses Typs gibt es aber in der Burg Eger, ${ }^{54}$ in Sárospatak ${ }^{55}$ und in Thürendorf in Transylvanien, ${ }^{56}$ wo die Anwesenheit von Wiedertäufern aufgrund von Schriftquellen und archäologischen Ergebnissen bewiesen ist. Die Čabrader Exemplare stammen trotzdem von einem anderen Modell, einer sog. Matrize, und die Herstellungsart der Kacheln weicht voneinander ab. Der Typ 1/7 ist auf der Burg Füzér ${ }^{57}$ und im Schloss von Thürendorf, ${ }^{58}$ wo die Ofenkacheln als Habanerprodukt identifiziert wurden, und auf den Öfen von Bibersburg und von Krásna Hôrka vorhanden. Diese Exemplare unterscheiden sich aber vom Čabrad’er Typ.

Es stellt sich also die Frage, von wem diese Öfen und Ofenkacheln hergestellt wurden und ob sie Habanerprodukten sind. Anhand neuer petrografischer Untersuchungen ${ }^{59}$ stehen die Öfen mit blauen Gefäßen des 18. Jahrhunderts in Verbindung, ${ }^{60}$ die auch als Produkte der Habaner identifiziert wurden. ${ }^{61}$ Eine Lokalisierung dieser Werkstatt oder der Werkstätten wurde schon Ende des 19. Jahrhunderts versucht. ${ }^{62}$ Später beschäftigte sich Béla Krisztinkovich mit der Frage ${ }^{63}$ Im letzten Jahrzehnt schrieben Gabriella Vida ${ }^{64}$ und Irena Pišutová ${ }^{65}$ je einen Bericht zu diesem Thema. Man war mehrheitlich der Meinung, dass die Werkstätten in Nordungarn, vermutlich in einer Bergbaustadt wie Neusohl oder Kremnitz (Kremnica/ Körmöcbánya), zu suchen sind.

49 Fejős 2007, 72, Kat. 81.

50 Pajer 1998, 66, Abb. 5.

51 DÖRY 2005, 205; HupKo 2013, 79.

52 LANDSFELD 1970, 22-23; PAJER 1983, 103-104.

53 DöRY 2005, 195.

54 Unpubliziert. Burg Eger, 2017. Ausgrabungsleiter: Gergely Buzás. Herzlichen Dank Gergely Buzás, Edit Kocsis und Melinda Síkéné Kovács für die Informationen!

55 Ringer 2014.

56 KÉMENES 2002.

57 GYuricza 1992, Kat. 97.

58 KÉmENEs 2002.

59 „A magyarországi köz-és magángyüjteményekben fellelheto habán kerámiák müvészettörténeti és archeometriai kutatása, számitógépes adatbázis és szakkatalógus elkészitése”. Projektzahl: 81133.

60 Ridovics et al. 2017, 221.

61 Pišutová 2014.

62 SZENDREI 1889.

63 Ridovics et al. 2015, 499.

64 FEJős 2008, 166.

65 Pišutová 2014, 125, 128. 
Allerdings konzentrierten sich die Forscher bei der Untersuchung der Werkstätte(n) nur auf die in Sammlungen aufbewahrten Gefäße; den Öfen wurde weniger Beachtung geschenkt. Nach Meinung der Verfasserin muss man die Kachel- und die Geschirrkeramik jedoch voneinander trennen. Heřman Landsfeld hielt z. B. die blauen Gefäße nicht für ein Produkt der Habaner ${ }^{66}$ er bezeichnete die Öfen aber als die einzigen, noch stehenden Habaner-Öfen. ${ }^{67}$ Auch die archäologischen Forschungen sprechen für eine Trennung des Fundmaterials. In Mähren gab es z. B. spezialisierte Werkstätten, in Altenmarkt dominierten die Ofenkacheln, ${ }^{68}$ während in Tracht (Strachotín) eher Gefäßfragmente zu verzeichnen sind. ${ }^{69}$

Bei der Datierung ist es wichtig, die Öfen von anderer Keramik getrennt zu interpretieren. Auf der Geschirrkeramik steht manchmal eine Jahreszahl, mit der die Gefäße besser datiert werden können. So wird die Herstellungszeit dieser blauen Geschirre zwischen 1695 und 1770 eingeordnet..$^{70}$ Öfen und Ofenkacheln wurden nicht mit Jahreszahlen versehen, sodass eine genaue Datierung offen bleiben muss. Sie wurden bisher nur mit kunsthistorischen, d. h. stilkritischen Methoden datiert. So wurde z. B. der Ofen von Trstené in den 1960er-Jahren noch um 1580 datiert, ${ }^{71}$ nach neueren Untersuchungen entstand er aber erst $1720 .{ }^{72}$ Der Ofen von Neusohl wurde zuerst von Imre Hol und Pál Voit auf das 17. Jahrhundert ${ }^{73}$ und später von József Katona, ${ }^{74}$ László Réti und Diána Radványi in das letzte Jahrzehnt des 17. Jahrhunderts datiert..$^{75}$ Der Fayenceofen im Schloss Weinitz entstand um $1640-1650 .{ }^{76}$ Die Ofenkacheln aus der Burg Füzér datierte Zoltán Simon nach historischen Angaben auf um 1640, weil die Besitzerfamilie der Burg Nádasdy Verbindungen zu den Habanern pflegte. ${ }^{77}$ Mónika Kémenes war der Ansicht, dass der Ofen von Thürendorf Ende des 17. Jahrhunderts hergestellt worden sei. ${ }^{78}$ Die Kacheln in der Burg Diósgyőr stammen aus der zweiten Hälfte des 17. Jahrhunderts. ${ }^{79}$

Die Čabrad’er Typen sind gute Vergleichsbeispiele für die erwähnten „Habaner“-Öfen; sie stammen aus einer archäologischen Grabung. Die Ofenkacheln fand man in der Auffüllung der Wolfsgrube vor dem zweiten Torturm. Diese Auffüllung entstand aufgrund der hier gefundenen Münzen und der Keramik in der ersten Hälfte des 18. Jahrhunderts. Diese Beobachtung passt gut zu den schriftlichen Quellen, da der Besitzer der Burg - die Familie Koháry - zu dieser Zeit ihre Residenz nach Sankt Anton in der Au (Svätý Anton/Szentantal) verlegte und die Burg Čabrad' geräumt wurde. ${ }^{80}$ In diese Zeit ist also die Zerstörung der Öfen zu setzen.

Historische Daten helfen aber auch bei der Frage, wann die Öfen aufgestellt wurden. Nach 1657 wurde István Koháry zum Kommandanten der Festung Fileck (Fil'akovo/Fülek) ernannt. ${ }^{81}$

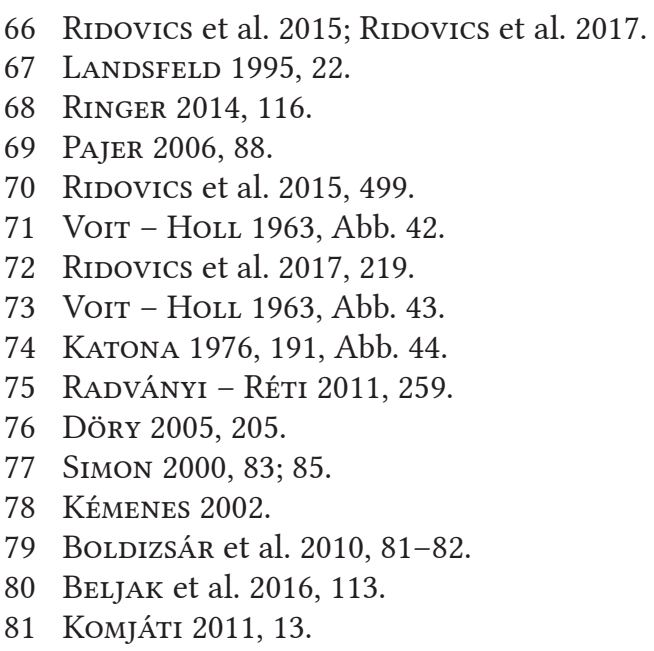


So bildet diese Befestigung einen guten Vergleich zur Čabrader Burg, weil beide im Besitz der Familie Koháry waren. Aus der Burg Fileck sind aber keine ähnlichen Ofenkacheln bekannt. So wären diese Ofentypen erst nach der Zerstörung von Fileck 1682 entstanden. ${ }^{82}$ Dies ist aber ein zu später Zeitpunkt für die Aufstellung der Öfen, da ihre Kacheln spätestens Mitte des 18. Jahrhunderts schon in die Wolfsgrube gelangten. Čabrad' war aber in dieser Zeit die Hauptresidenz der Familie Koháry, während Fileck als Grenzburg gegen Türken diente. Zwischen 1665 und 1670 hielt sich ein großes Kontingent von Soldaten auf der Festung auf, um deren Versorgung man sich aber nicht zufriedenstellend kümmerte. ${ }^{83}$ Man konnte also kaum aufwändige Öfen ${ }^{84}$ auf der Burg aufstellen, während die Soldaten hungerten. Auch die Burg selbst war nicht gut befestigt.

Die Datierung ins 17. Jahrhundert wird durch Schriftquellen belegt. Um 1720, dem mutmaßlichen Entstehungszeitpunkt des Ofens von Trstené, taucht die neue Residenz in Sankt Anton auf. Daher wurden, nach Meinung der Verfasserin, keine qualitätsvollen Öfen erbaut, als die Familie nach Sankt Anton umzog. In den Quellen aus dieser Zeit geht es lediglich um Verbesserungen an bestehenden Öfen, nicht um das Aufstellen neuer Öfen ${ }^{85}$ Die polychromen Ofenkacheln aus der Burg Eger beweisen diese Datierung. Aufgrund der archäologischen Ergebnisse wurde der Ofen beim Brand 1694 zerstört, also hat er in der zweiten Hälfte des 17. Jahrhunderts noch gestanden. ${ }^{86}$

Obwohl die grünglasierte Gruppe einen vereinfachten Motivschatz zeigt, wurden die grünen Öfen vermutlich gleichzeitig mit den Fayenceöfen genutzt, da die grünglasierten sowie die blau- und weißglasierten Ofenkacheln aus der Wolfsgrube zusammen und vermischt vorkommen. Daher kann man die Ofenkacheln in die zweite Hälfte des 17. Jahrhunderts datieren. Für eine genauere zeitliche Eingrenzung müsste man weitere Ofenkachelfunde aus Nordungarn bearbeiten.

Die Frage, ob die Kacheln von den Habanern hergestellt wurden, kann abschließend noch nicht eindeutig beantwortet werden. Sicher ist, dass ihre Motive in den Habanerwerkstätten in Mähren und auch in Sárospatak gänzlich unbekannt waren. Tatsächlich kommen nur der Typ 1/5 und die Herzreihe vom Typ 1/8 in den Habanerwerkstätten vor. Auch für Ungarn ist mit Fayence-Werkstätten zu rechnen. In der Schweiz und in Deutschland erschienen FayenceÖfen schon im 16. Jahrhundert, und die Forschung geht davon aus, dass es Fayence-Hafner gab, ${ }^{87}$ weil diese aus den schriftlichen Quellen namentlich bekannt sind ${ }^{88}$ Obwohl für Ungarn keine schriftlichen Daten zu Fayence-Töpfereien vorliegen, können neben den Habaner-Werkstätten im 17. Jahrhundert auch ungarische Fayence-Hafnereien vermutet werden. Da die Analogien aus verschiedenem Modellen stammen, ist von mehreren Fayence-Werkstätten auszugehen, allerdings ist deren Lokalisierung noch fraglich.

82 КомjÁti 2011, 8.

83 KomjÁti 2010, 94-95.

84 FEJős 2008, 165.

85 ŠA BB, KC, Pars II. Rationes 1703, 1708, 1710, 1716, 1718, 1721, 1724, 1726; Rationes super proventibus ex Dominiis Szitnensi, Csabraghiensi et Diviniensi [...] Pro Anno 1716

86 Kocsis, Edit: Előzetes jelentés az egri vár 2017-es ásatásából származó kályhacsempékről (Fundbericht über die Ofenkacheln von der Ausgrabung der Burg Eger im Jahre 2017). Manuskript.

87 KISS - SPEKNER - VÉGH 2018, 39.

88 Roth HeEge 2018, 34-35. 
Die dritte Gruppe ist sehr bruchstückhaft und von schlechterer Qualität. Es scheint sich um einen Versuch zu handeln, die Fayenceprodukte zu imitieren. Die Kacheln sollten wahrscheinlich als Ersatzstücke für die bestehenden Öfen dienen. Sie sind daher ins Ende des 17. Jahrhunderts zu datieren. An der Wende vom 17. zum 18. Jahrhundert wurden auf der Burg einfache, nur mit Glasuren und ohne Relief verzierte Öfen aufgestellt, deren Oberflächen weiß engobiert mit blauen und durchsichtigen Glasuren - sich ähneln. Die Datierung wird durch Schriftquellen gestützt. Im Jahre 1709 wurde blaue Farbe für die Öfen des Palastes gekauft, und im selben Jahre wurden die Öfen repariert. ${ }^{89}$ Ende des 17. Jahrhunderts, als von einer Reparatur der Heizanlagen berichtet wurde, aber bereits die Räumung der Burg begann, sollten möglicherweise diese Ersatzkacheln verwendet werden.

\section{Literatur}

Beljak, J. - Maliniak, P. - Mordovin, M. - Šimkovic, M. 2016: Výskum tretej (pôvodne hornej) brány hradu Čabrad'v rokoch 2013-2015. Archaeologia historica 41/2, 99-132.

Boldizsár P. - Kocsis E. - SABjÁn T. 2010: A diósgyőri vár 16-17. századi kályhacsempéi. Miskolc.

ČURNÝ, M. 2004: Keramika zo 16.-18. stor. na juhozápadnom Slovensku na príklade nálezov z kaštiela v Lukáčovciach. Master-Diplomarbeit. Manuskript. Nitra.

Divald K. 1929: A magyar iparmüvészet története. Budapest.

Döry, L. 2005: Vergessene und unbekannte Habaneröfen. In: EndRES, W. - GrIEshofer, F. (Hrsg.): Keramik als Zeichen regionaler Identität. Beiträge des 36. Internationalen Hafnerei-Symposiums des Arbeitskreises für Keramikforschung vom 21. bis 26. 9. 2003 in Kittsee. Wien-Kittsee, 185-205.

FEjős Z. (Szerk.) 2008: Legendás lények, varázslatos virágok - a közkedvelt reneszánsz. Budapest.

Gyuricza A. 1992: Reneszánsz kályhacsempék Északkelet-Magyarországon. Miskolc.

Homola, V. - Tомос̌Eк, O. 2017: Hrad L’upča klenot pohronia vo svetle vekov. Podbrezová.

Hupкo, D. 2013: Habánske kachlové pece z hradu Červený Kameň. História 50, 59-83.

Katona I. 1975: A habánok Egerben. Agria. Az Egri Múzeum Évkönyve 13, 125-142.

Katona I. 1976: A habán kerámia Magyarországon. Budapest.

Katona I. 1983: Habán múvészeti emlékek Magyarországon. Budapest.

Kémenes M. 2002: Magyarózd. A Radák-Pekri kastély központi pincehelyiségének 2002. évi kutatása. http://magyarozd.atw.hu/kastely/regeszet.htm (21.02.2020.)

KIsS V. - SPEKNER E. - VÉGH A. 2018: Szívmelengető középkor. Kályhák és kályhacsempék a középkori Magyarországon. 14-16. század. Budapest.

КомJÁті Z. I. 2010: „...Édes eleink véres verítékével szerzett, és eddig is fennálló nemesi szabadságunknak labefactáltatása...”. Koháry István füleki főkapitány (1667-1682) várőrségének nézeteltérései a Heves és Külső-Szolnok vármegyei magisztrátussal. Agria. Az Egri Múzeum Évkönyve 46, 93-114.

KомjÁti Z. I. 2011: A füleki végvár müködtetése Koháry II. István fökapitánysága idején (1667-1682). Dissertation. Manuskript. Debrecen.

Krisztinkovich, B. 1962. Haban Pottery. Budapest.

LANDSFeld, H. 1970: Habánské památky. Strážnice.

PAjer, J. 1983: Počátky novověké keramiky ve Strážnici. Strážnice.

PAJER, J. 1998: Novokřtěnci ve Stare Břeclavi. Jižní Morava 53-72.

89 Štátny Archív Banská Bystrica (Staatliches Archiv Banská Bystrica) fond rodiny Koháry-Coburg, Pars II. Difficultates 1708-1709. 
Pajer, J. 2006: Studie o Novokřtěních. Strážnice.

Pajer, J. 2011: Anabaptist faience from Moravia 1593-1620. Catalogue of documents from institutional and privat collections. Strážnice.

PIšutovÁ, I. 2014: Nové poznatky o habánoch a ich tvorbe na strednom Slovensku v 18. storočí. Etnografia 55, 113-136.

RAdvÁNYI, D. 2013: Fayencekachelöfen der Habaner, Ofenkacheln und ihre Rekonstruktionen in der Sammlung des Kunstgewerbemuseums zu Budapest. Ars Decorativa 29, 57-70.

Radványi D. - Rétr L. 2011: A habánok kerámiamúvészete. Budapest.

RAKonczAY, R. 2018: „Der Kachelofen des Erzbischofs“. Ofenkacheln aus der Burg Čabrad” (Slowakei) und der Kachelkreis von Neusohl um 1500. Burgen und Schlösser 59/4, 245-254.

Ridovics A. 2002: A Magyar Nemzeti Múzeum habán kerámiái a 17-18. századból. Folia Historica 23. 67-87.

Ridovics A. - MAy Z. - BAjnóczi B. 2017: Virágok, sellők, bányászkalapács. In: Ridovics A. BAjNóczi B. - DÁgi M. - Lővei P. (Hrsg.): Interdiszciplinaritás. Budapest, 195-225.

Ridovics, A. - May, Z. - BAjNóczi, B. - Tóth, M. 2015: Examination of Haban vessels with uraniumbearing blue glaze. Acta Ethnographica Hungarica 60/2, 485-515.

RINGER I. 2014: Uradalmi és mezővárosi múhelyek a 17. századi Sárospatakon. Dissertation. Manuskript. Budapest.

Roth Heege, E. 2012: Ofenkeramik und Kachelofen. Typologie, Terminologie und Rekonstruktion. Bern.

Roth HeEge, E. 2018: Kachelöfen in der Schweiz, Dekore und Formen von 1500 bis 1850. In: ŠREJBEROvÁ, J. (Ed.): Kachle a kachlová kamna - Ofenkachel und Kachelöfen. Most, 26-39.

Simon Z. 2000: A füzéri vár a 16-17. században. Miskolc.

SzENDREI J. 1889: A habánok története Magyarországon és a habán majolika. Müvészi Ipar 161-176.

Voit, P. - Holl, I. 1963: Alte ungarische Ofenkacheln. Budapest. 

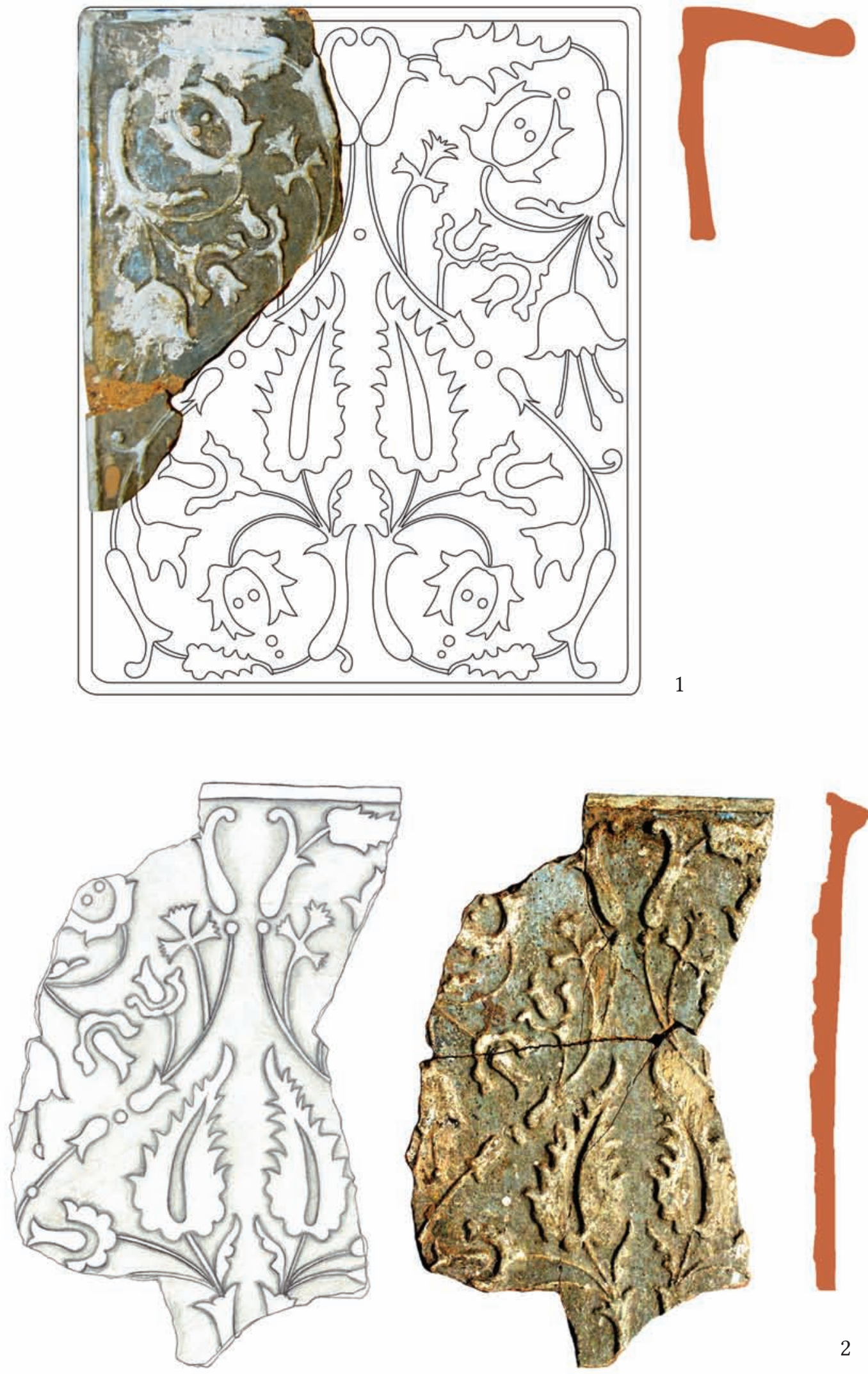

Abb. 13. Die Fayencekacheln auf der Burg Čabrad'. 1-2 - Der Typ 1/1. 

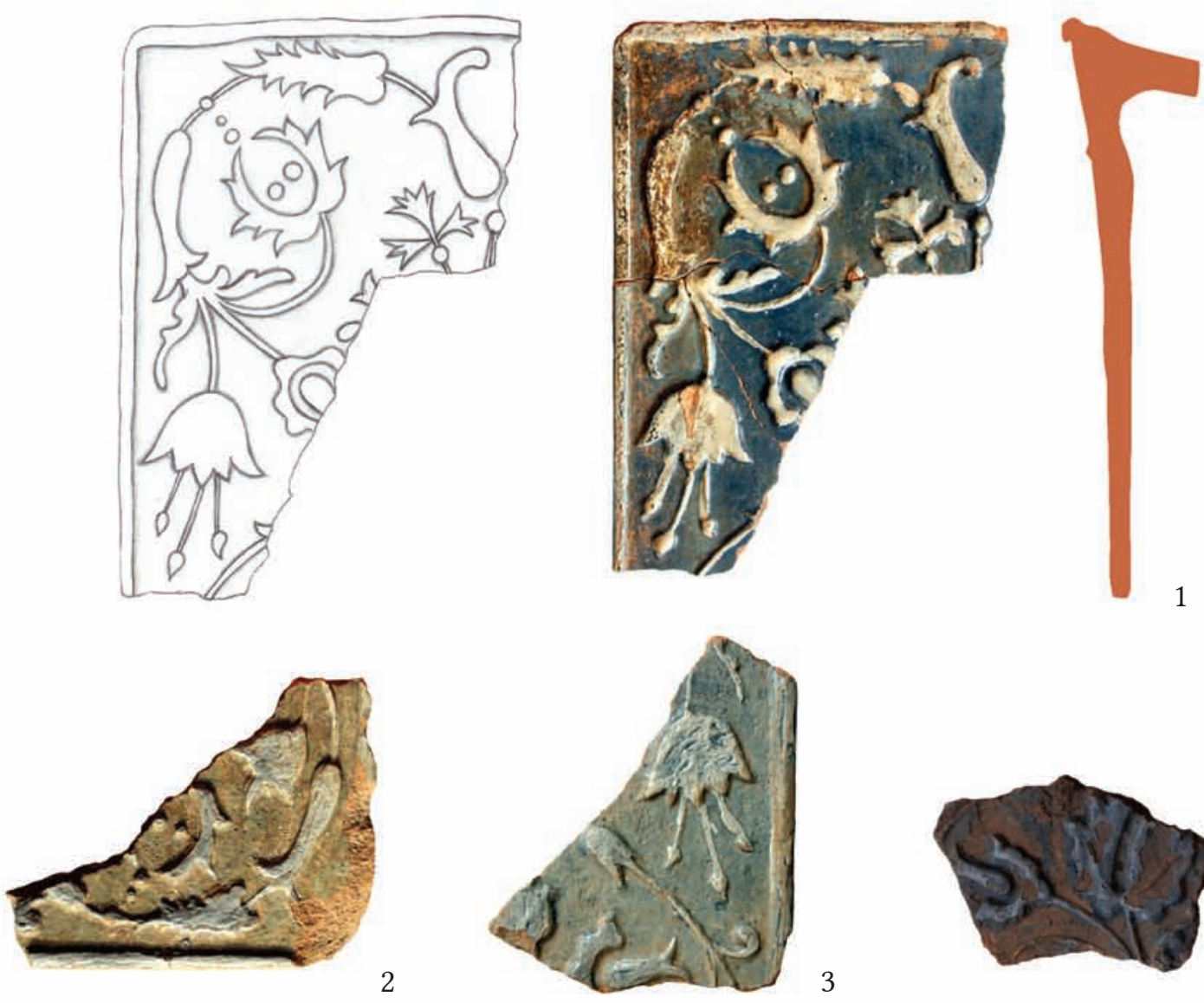

3
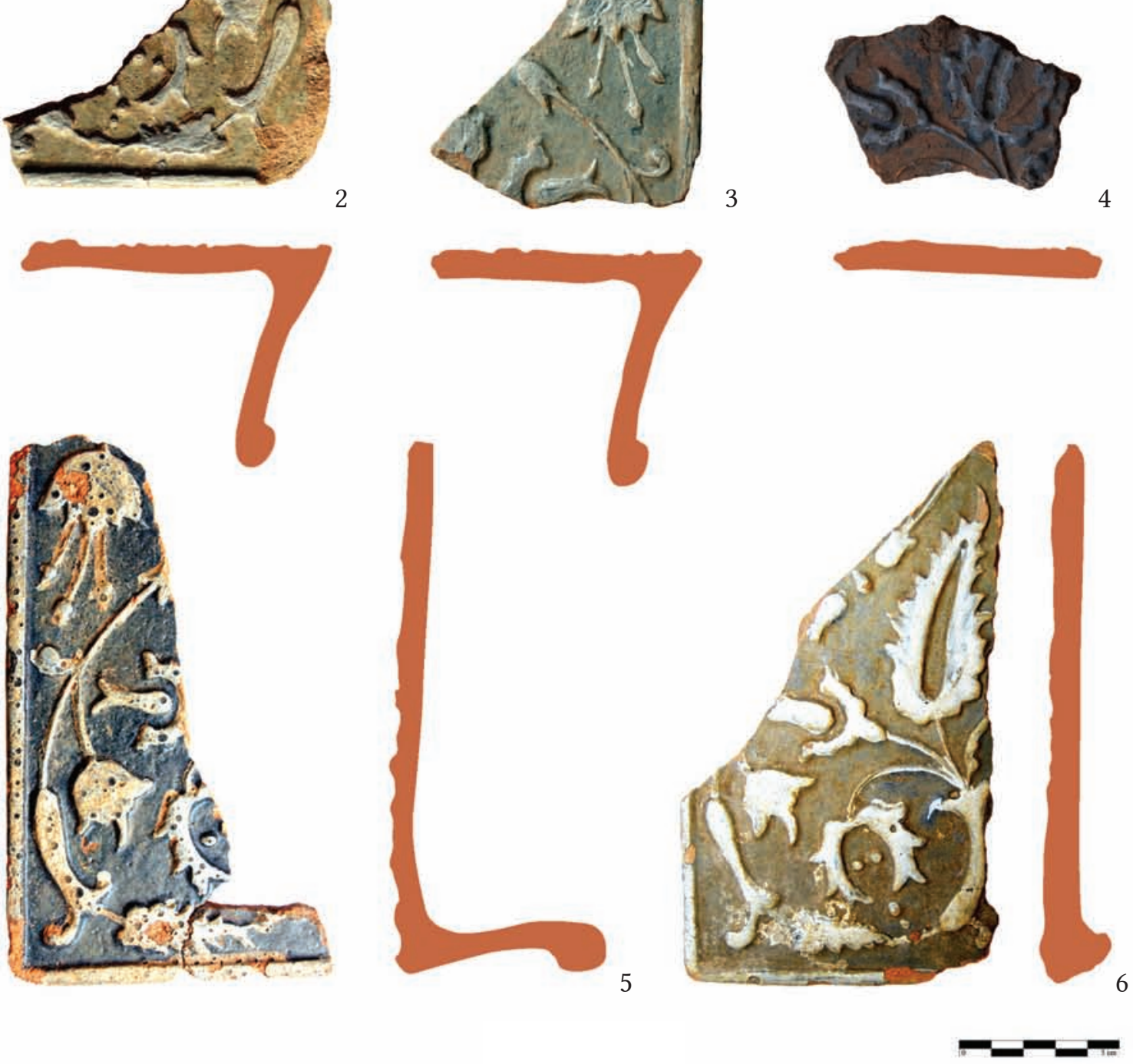

Abb. 14. Die Fayencekacheln auf der Burg Čabrad'. 1-6 - Der Typ 1/1. 

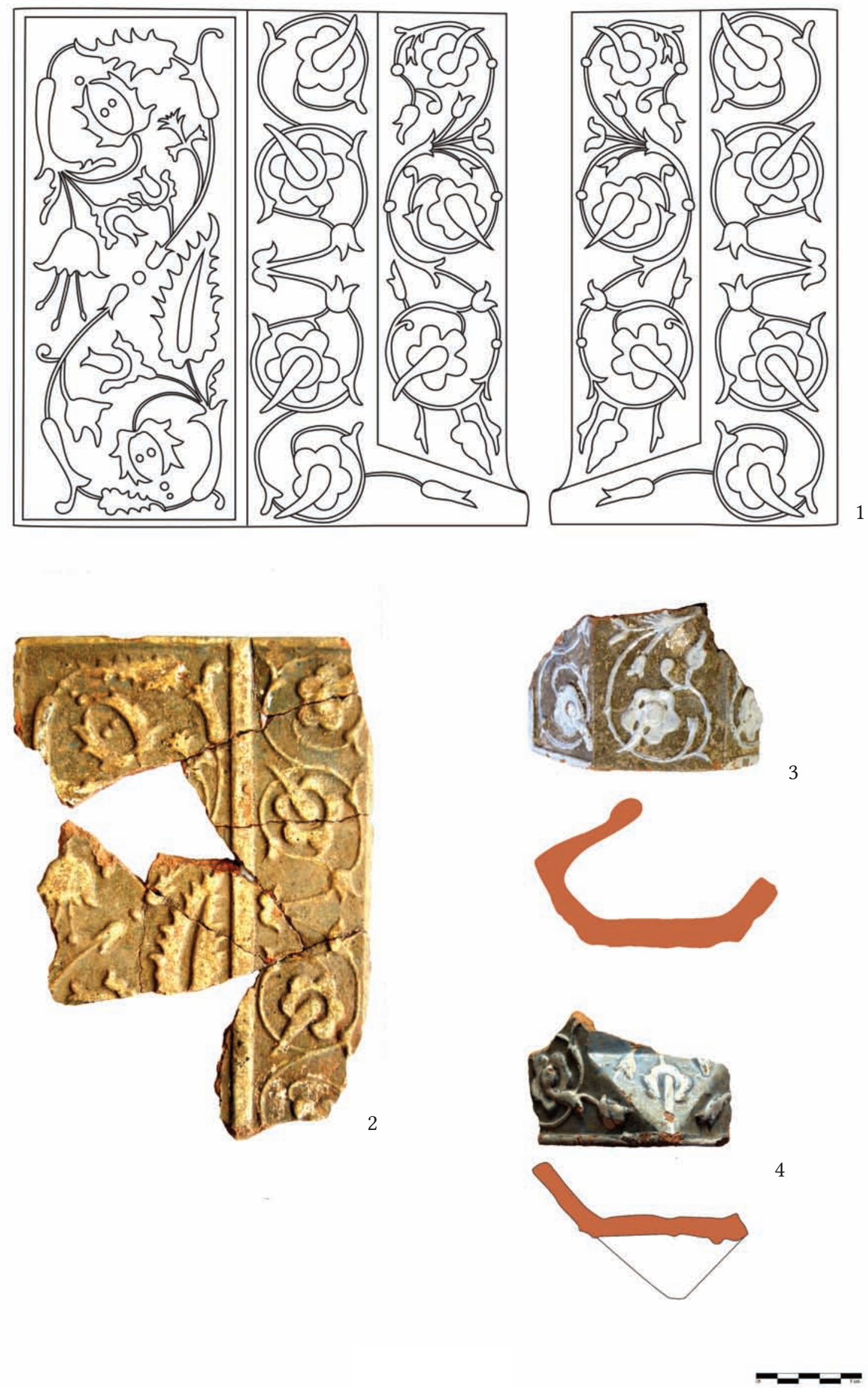

Abb. 15. Die Fayencekacheln auf der Burg Čabrad'. 1-4 - Der Typ 1/2. 

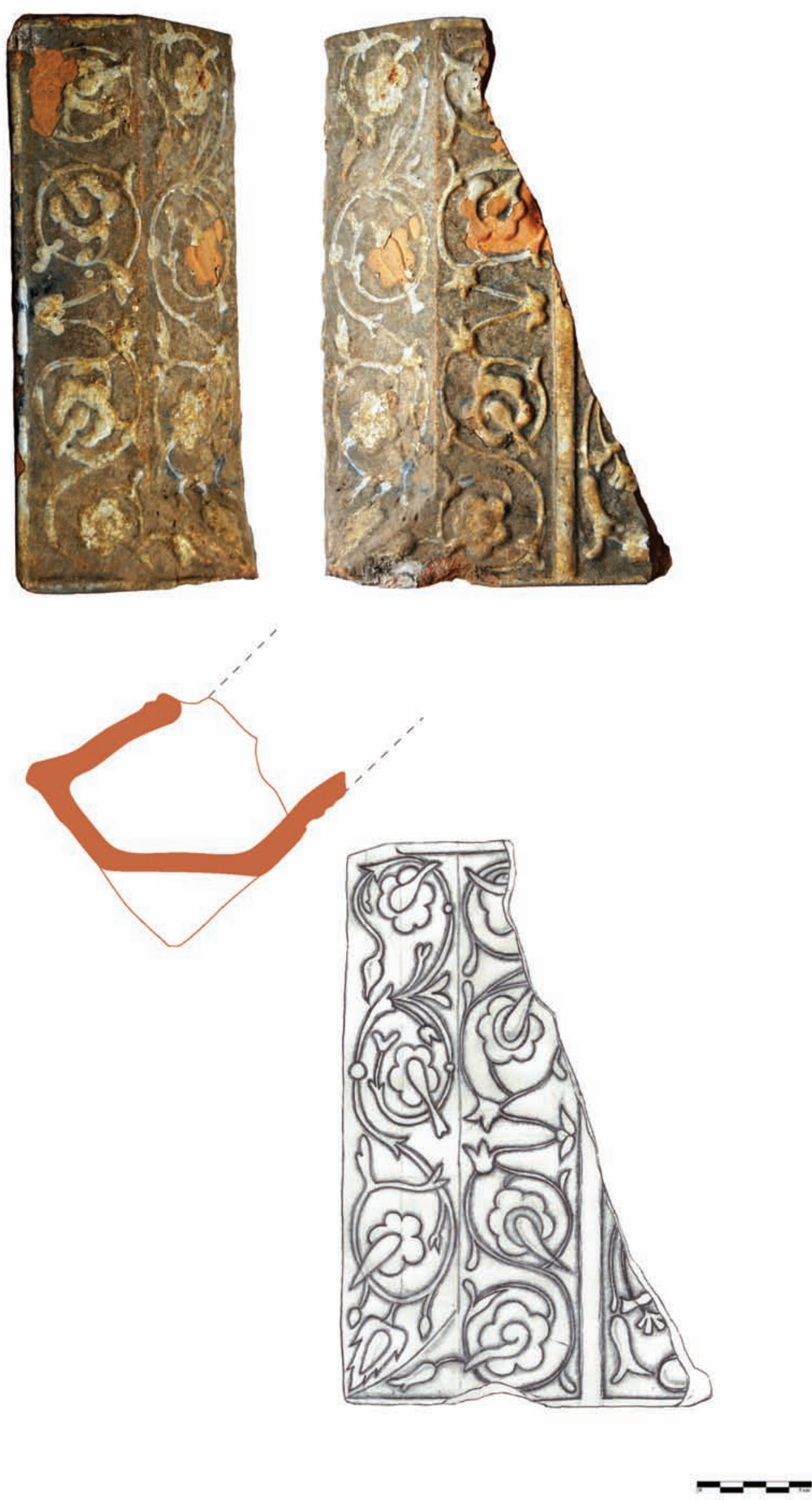

Abb. 16. Die Fayencekacheln auf der Burg Čabrad. Der Typ 1/2. 

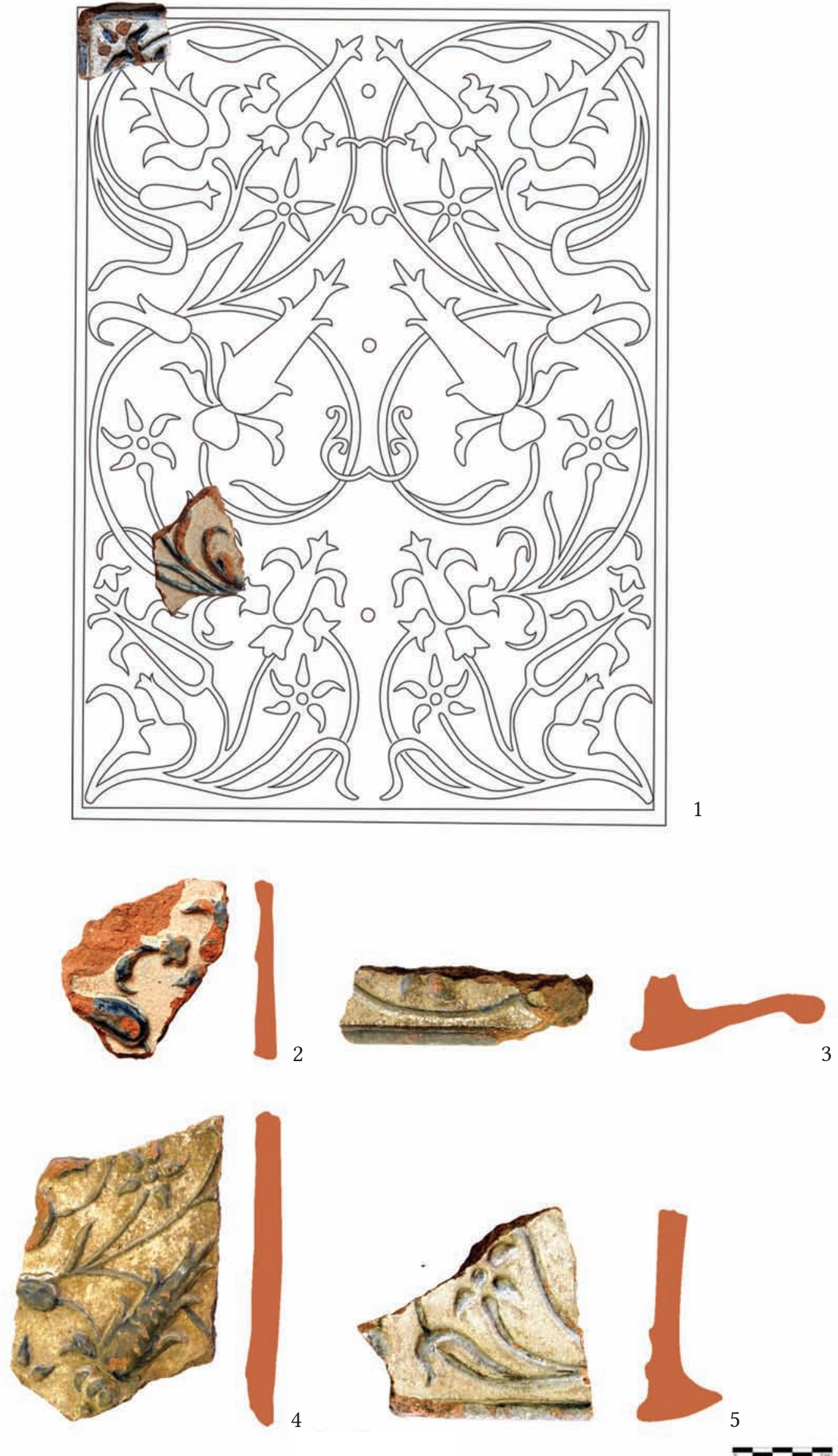

Abb. 17. Die Fayencekacheln auf der Burg Čabrad'. 1-5 - Der Typ 1/3. 

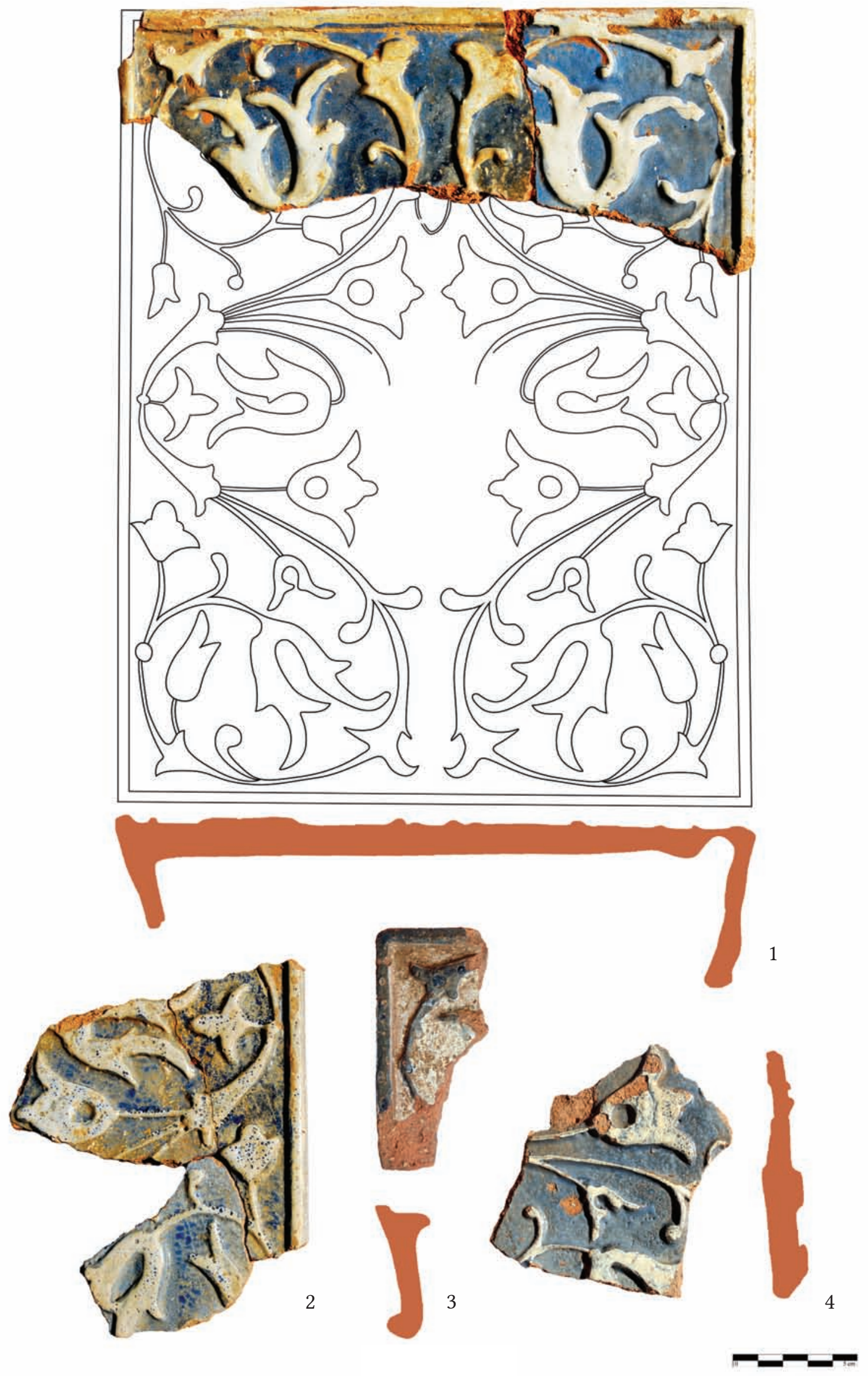

Abb. 18. Die Fayencekacheln auf der Burg Čabrad. 1-4 - Der Typ 1/4. 

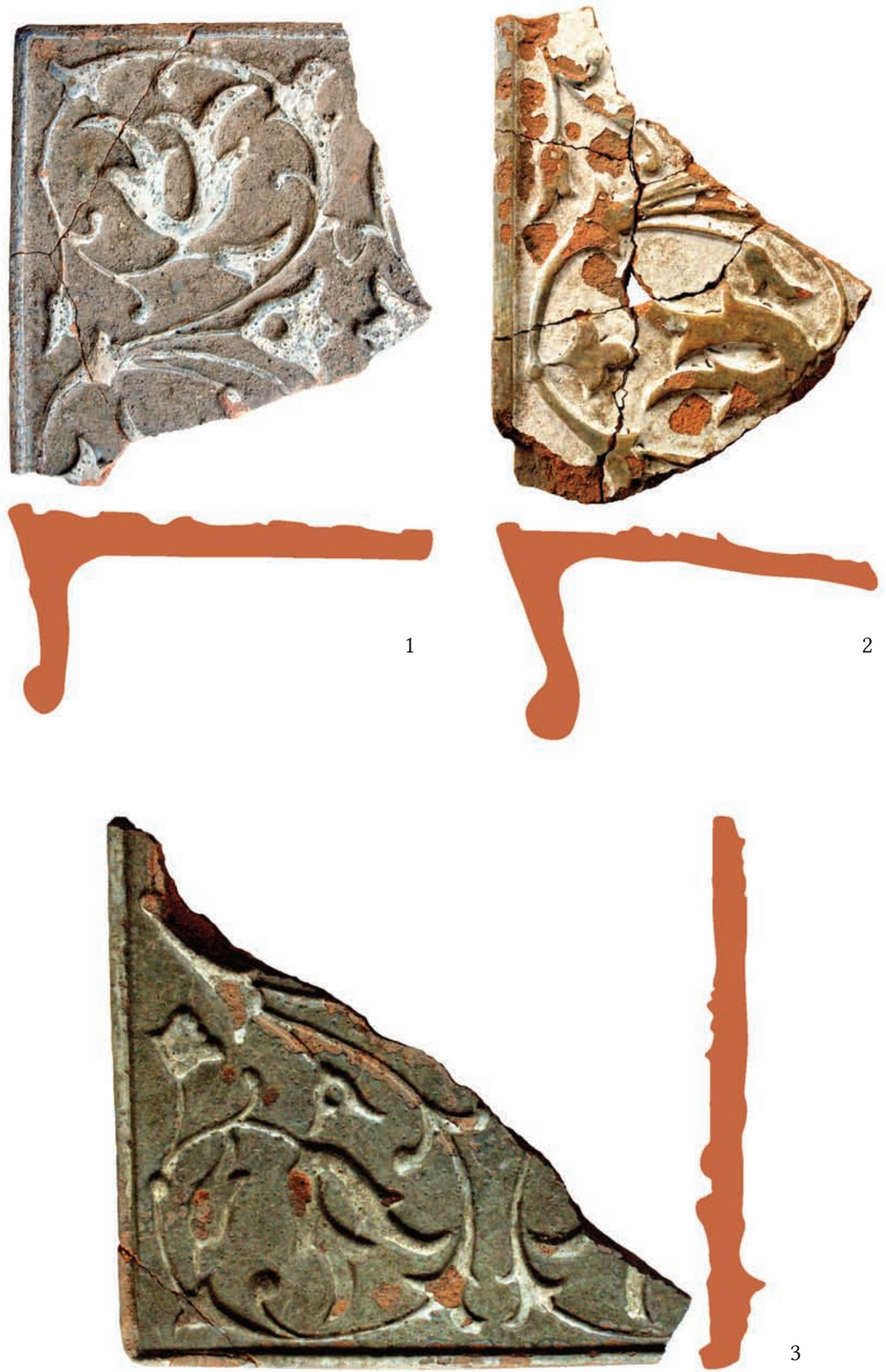

3

Abb. 19. Die Fayencekacheln auf der Burg Čabrad'. 1-3 - Der Typ 1/4. 

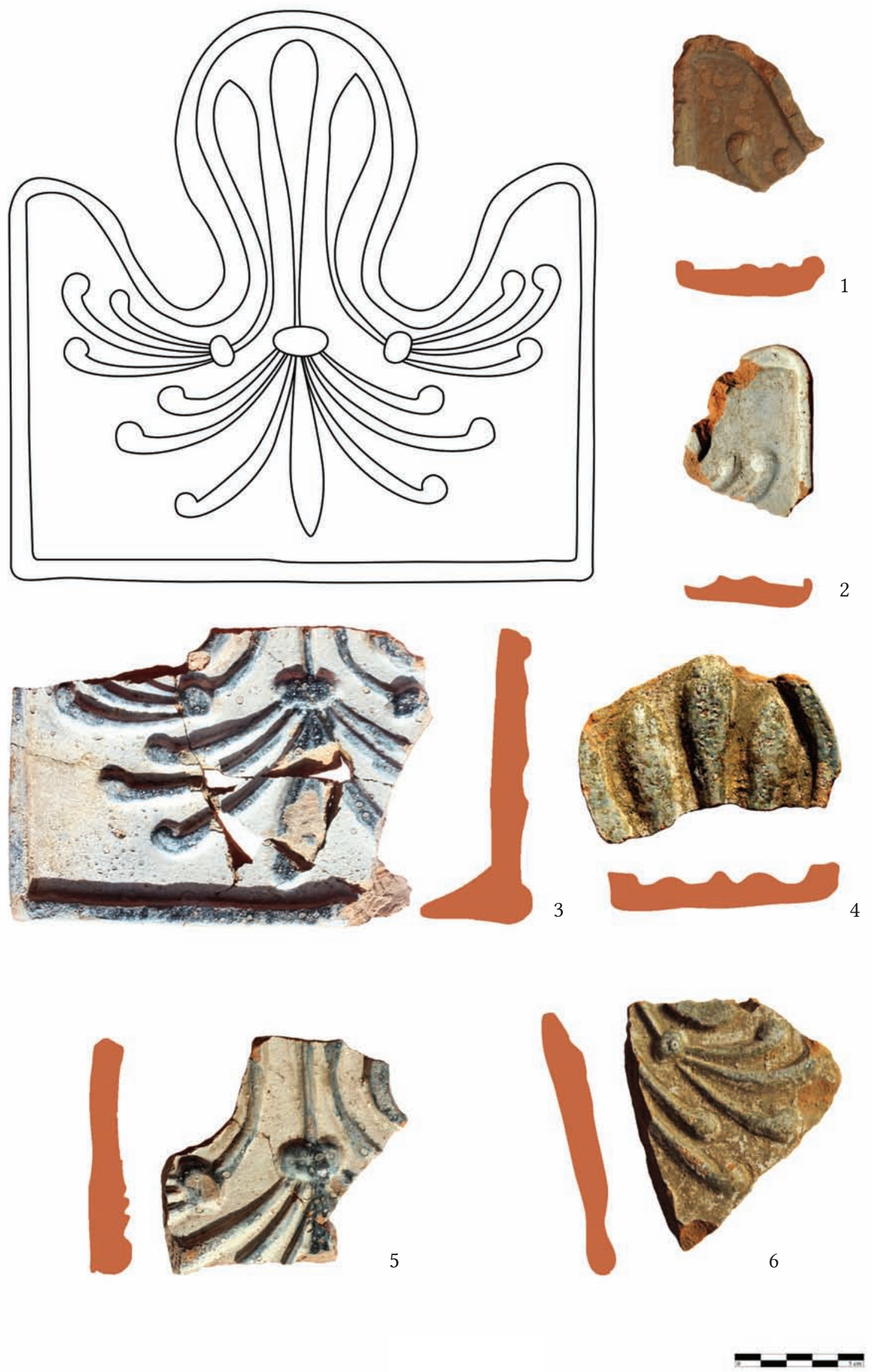

Abb. 20. Die Fayencekacheln auf der Burg Čabrad'. 1-7 - Der Typ 1/5. 

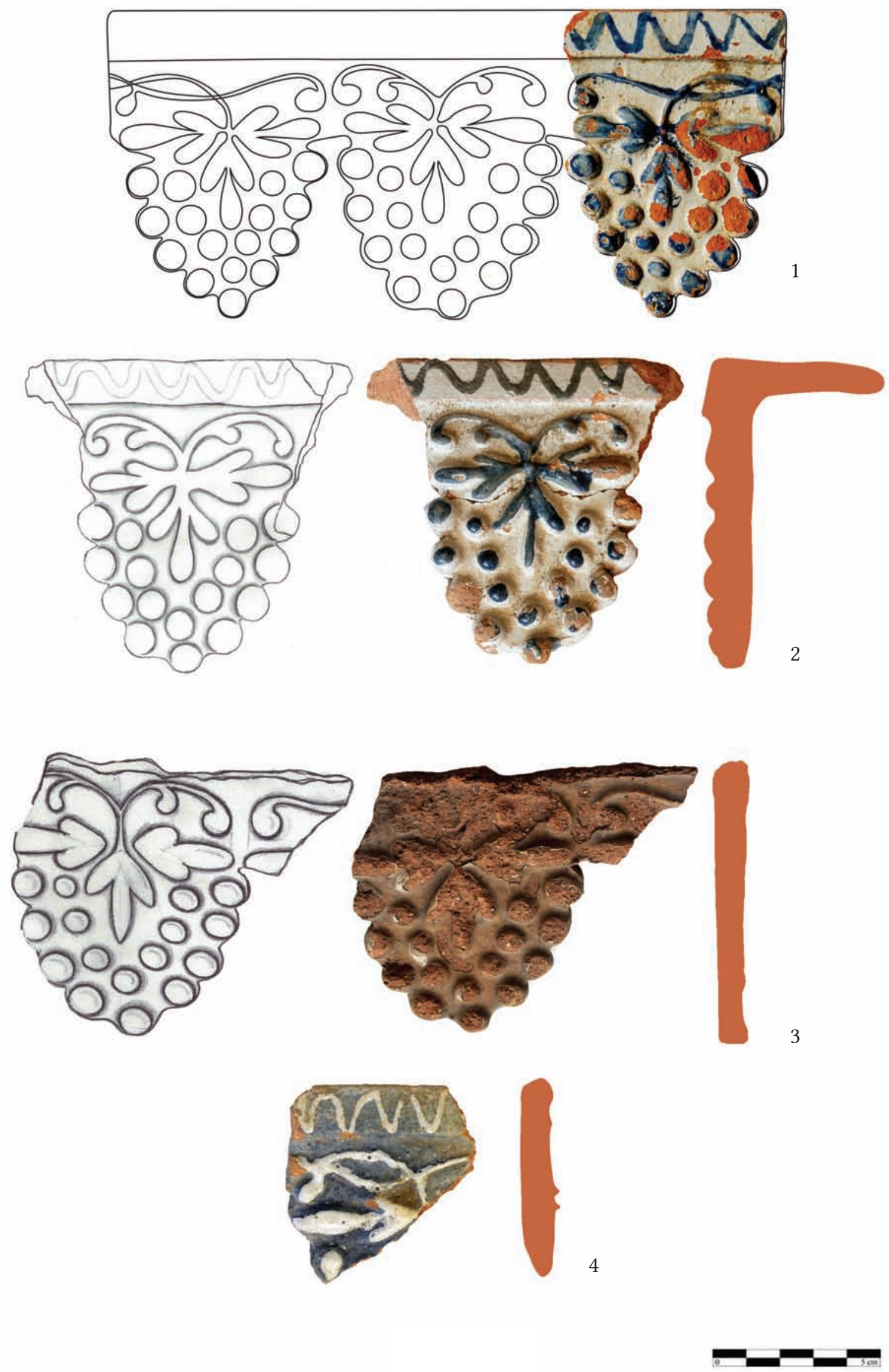

Abb. 21. Die Fayencekacheln auf der Burg Čabrad'. 1-4 - Der Typ 1/6. 

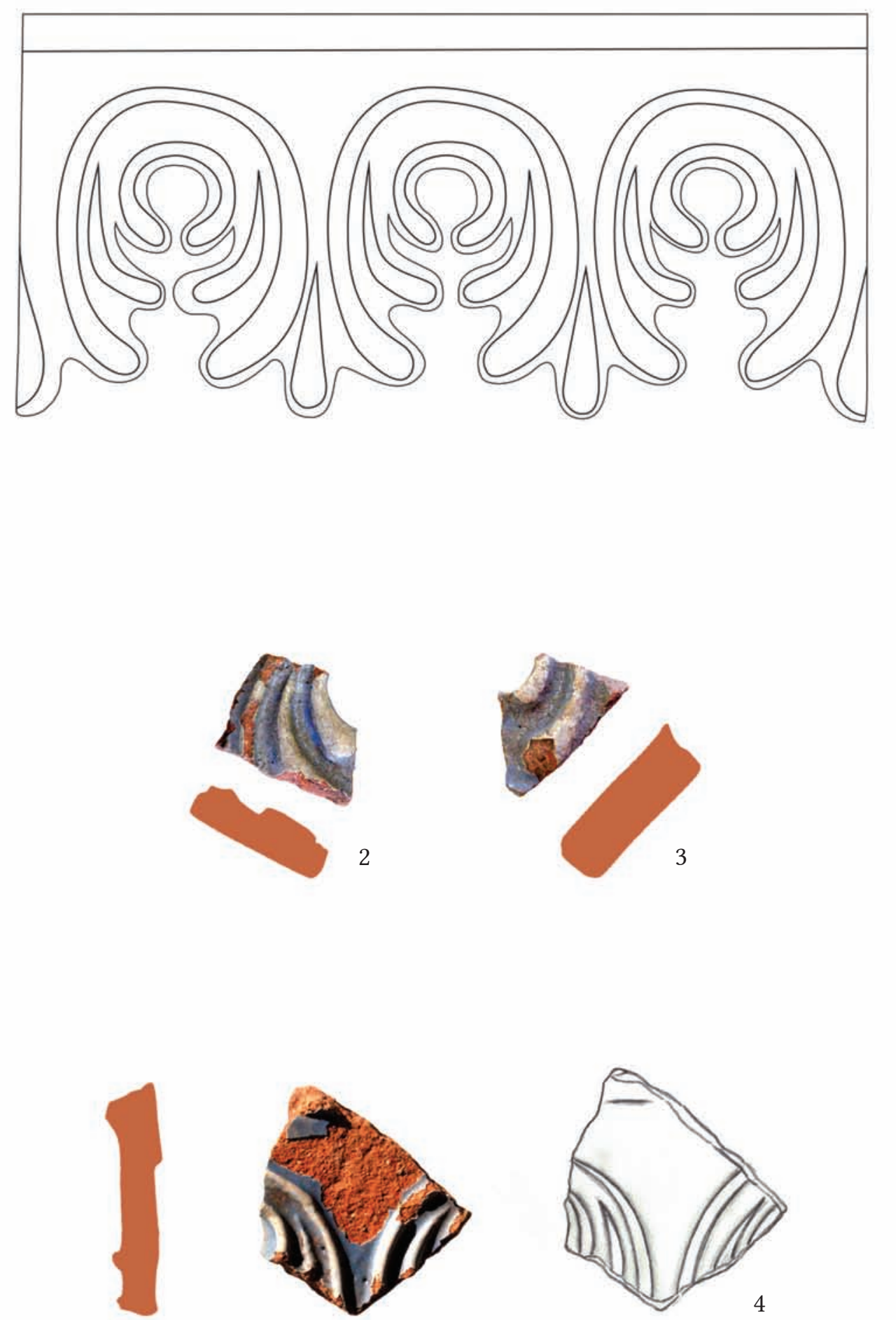

4

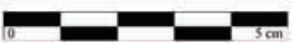

Abb. 22. Die Fayencekacheln auf der Burg Čabrad. 1-4 - Der Typ 1/7. 

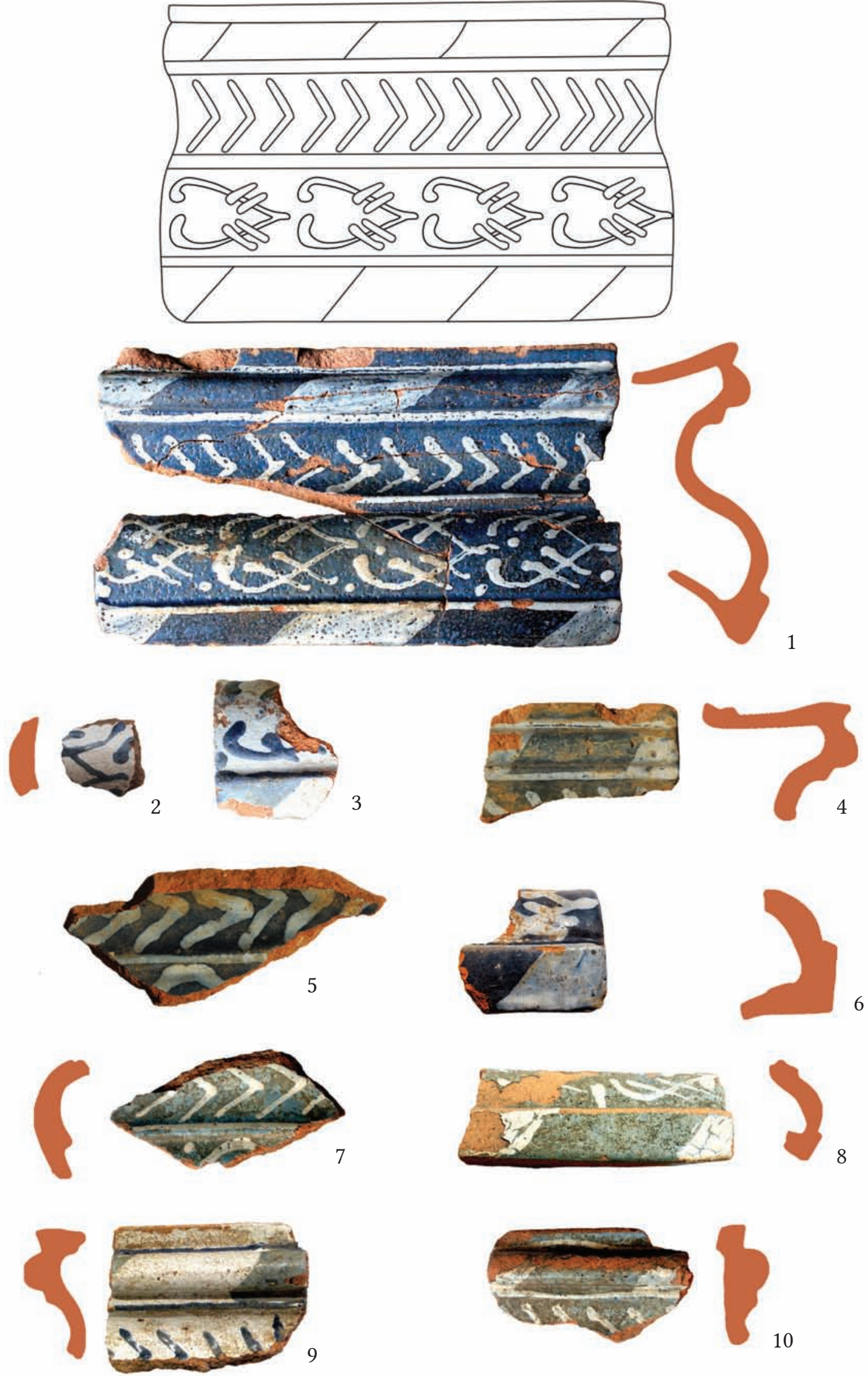

Abb. 23. Die Fayencekacheln auf der Burg Čabrad'. 1-9 - Der Typ 1/8. 

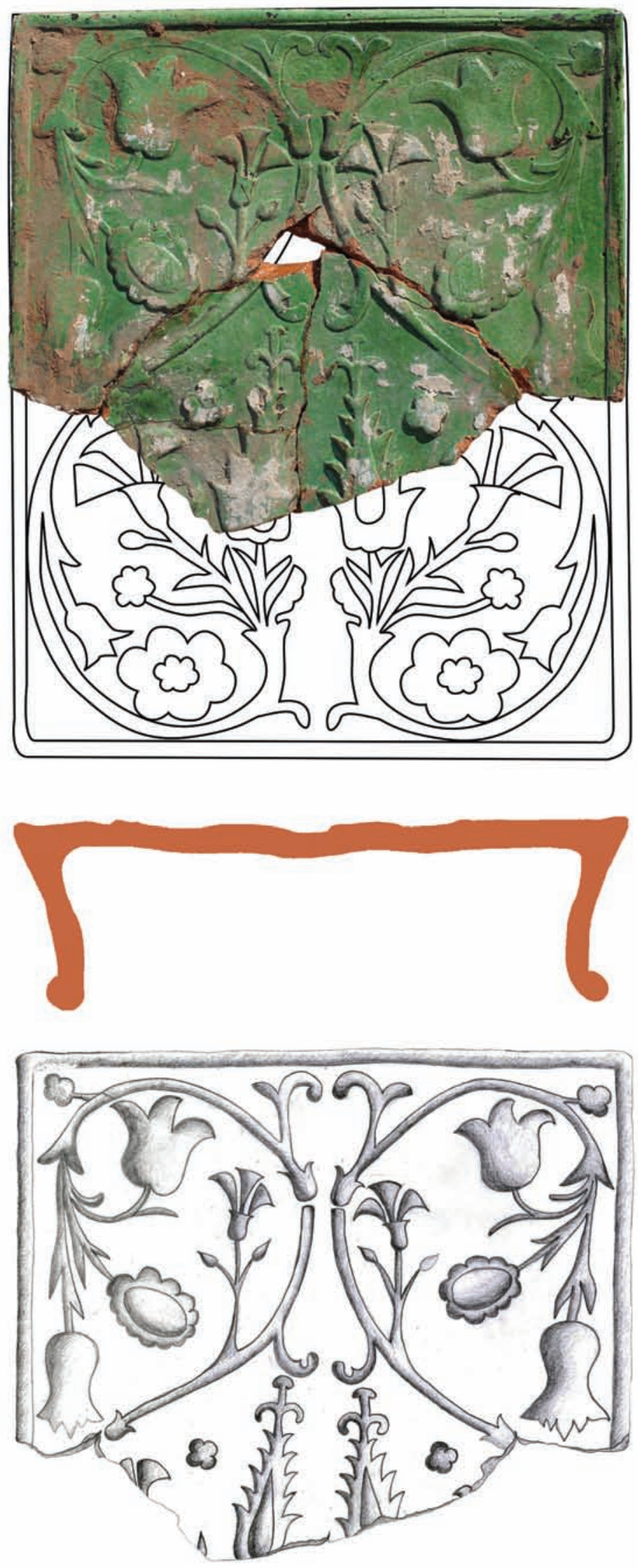

Abb. 24. Die grünglasierte Gruppe auf der Burg Čabrad. Der Typ 2/1. 

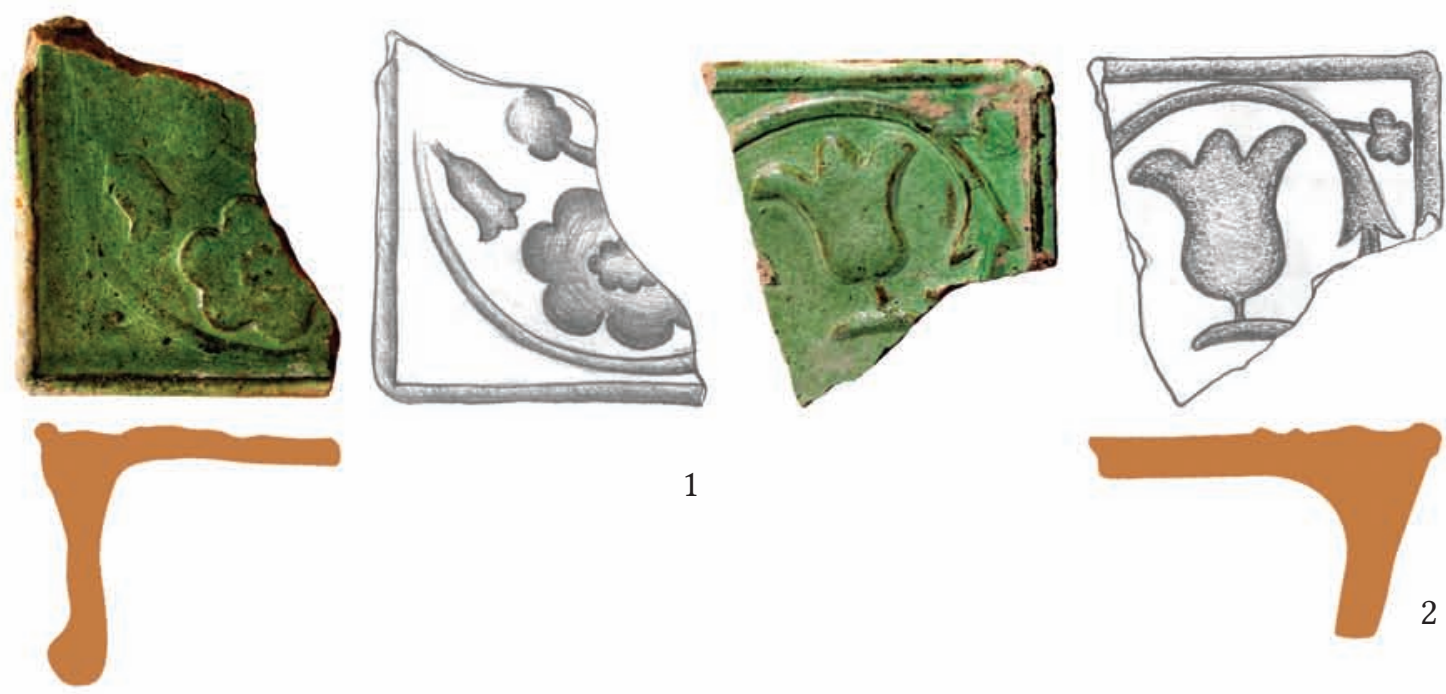

1
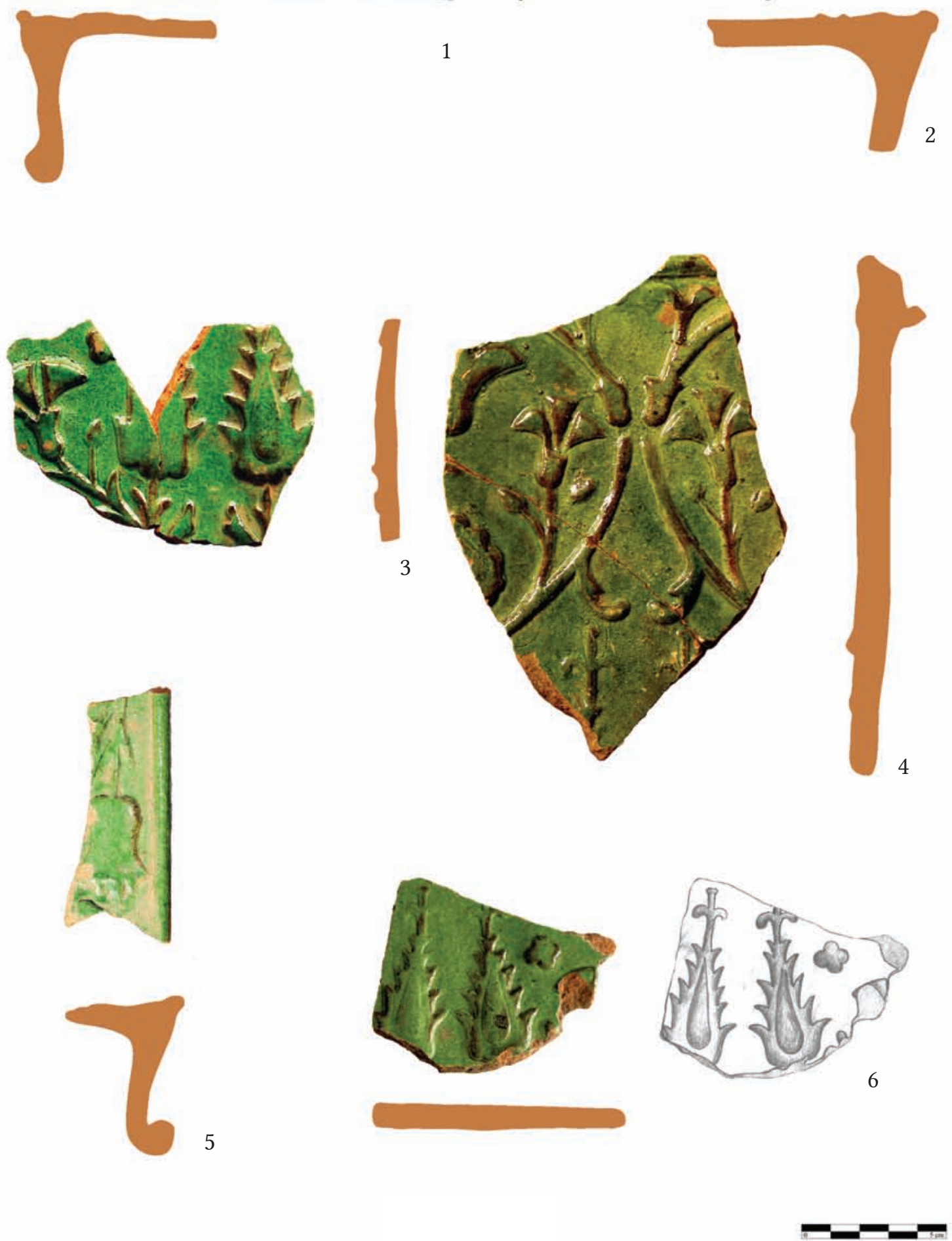

Abb. 25. Die grünglasierte Gruppe auf der Burg Čabrad'. 1-6 - Der Typ 2/1. 

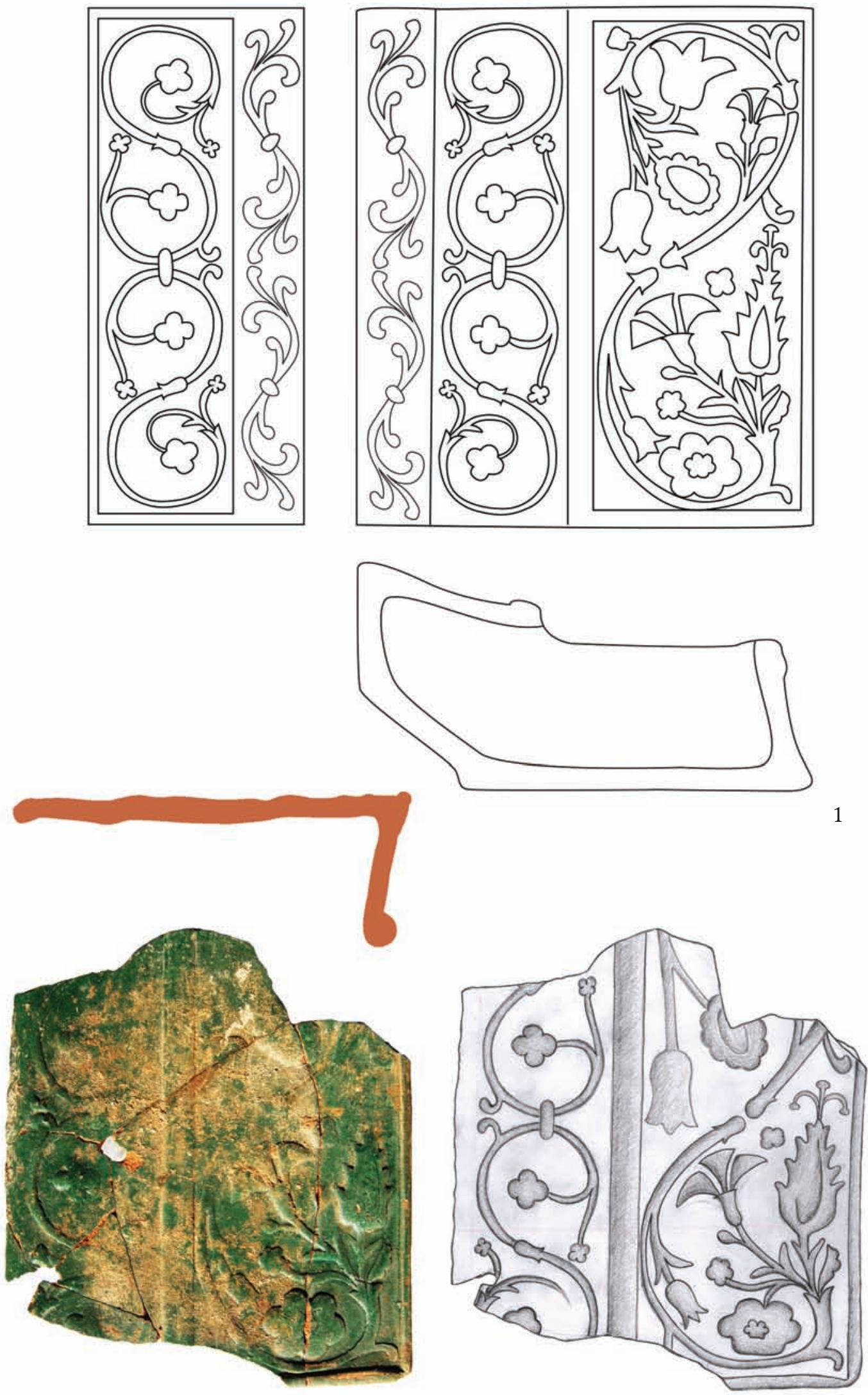

Abb. 26. Die grünglasierte Gruppe auf der Burg Čabrad’. 1-2 - Der Typ 2/2. 

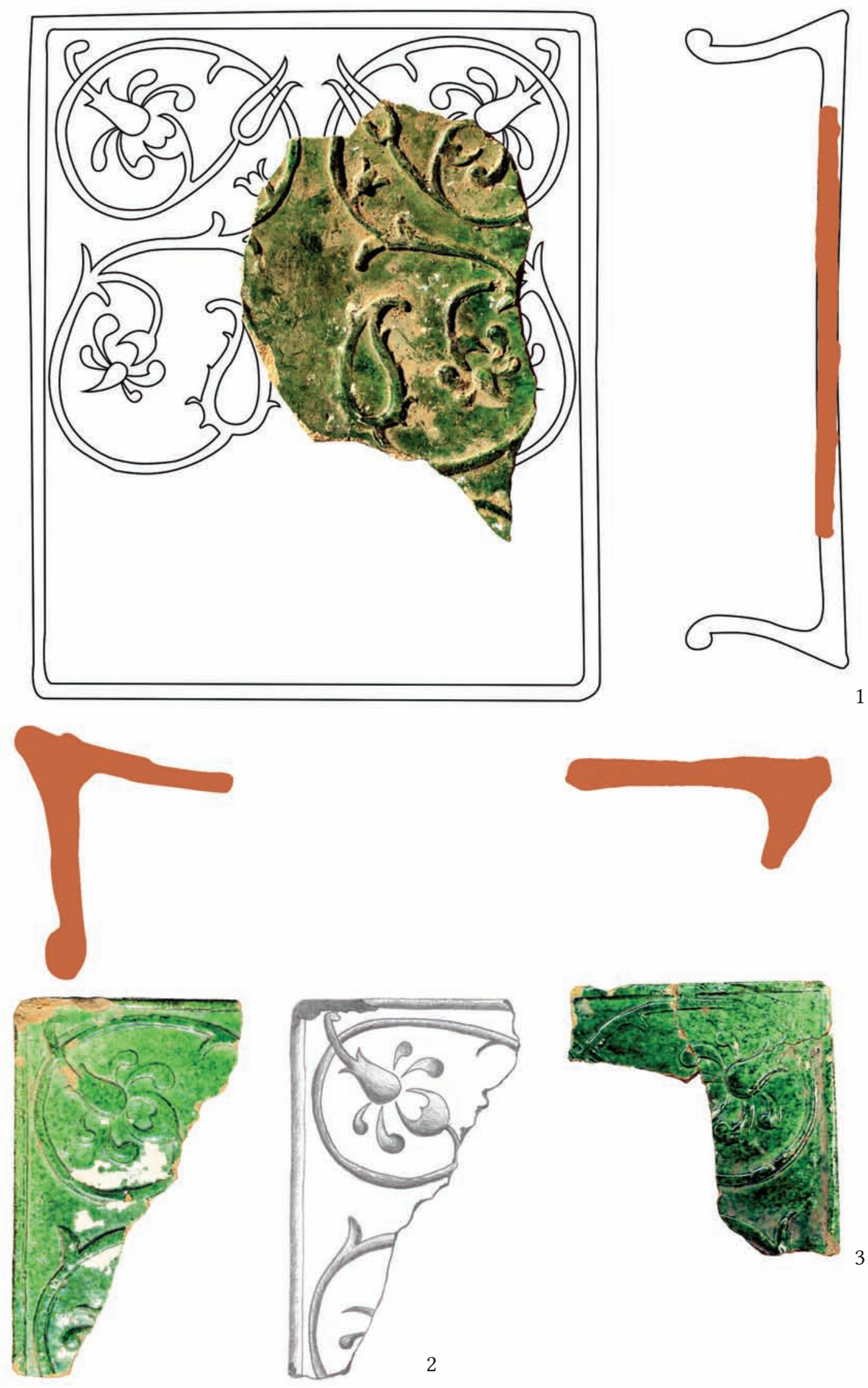

Abb. 27. Die grünglasierte Gruppe auf der Burg Čabrad'. 1-3 - Der Typ 2/3. 

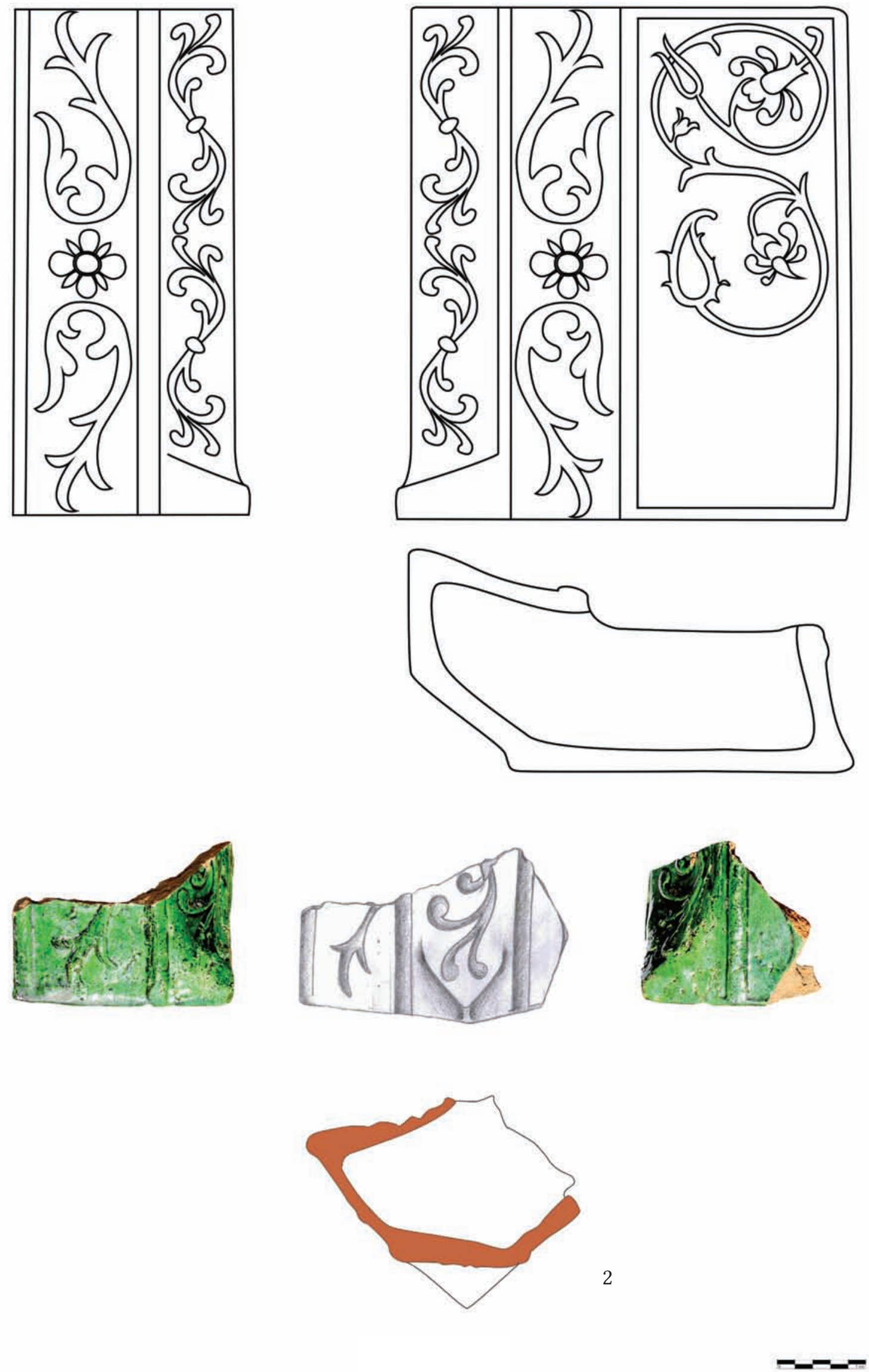

Abb. 28. Die grünglasierte Gruppe auf der Burg Čabrad’. 1-2 - Der Typ 2/4. 

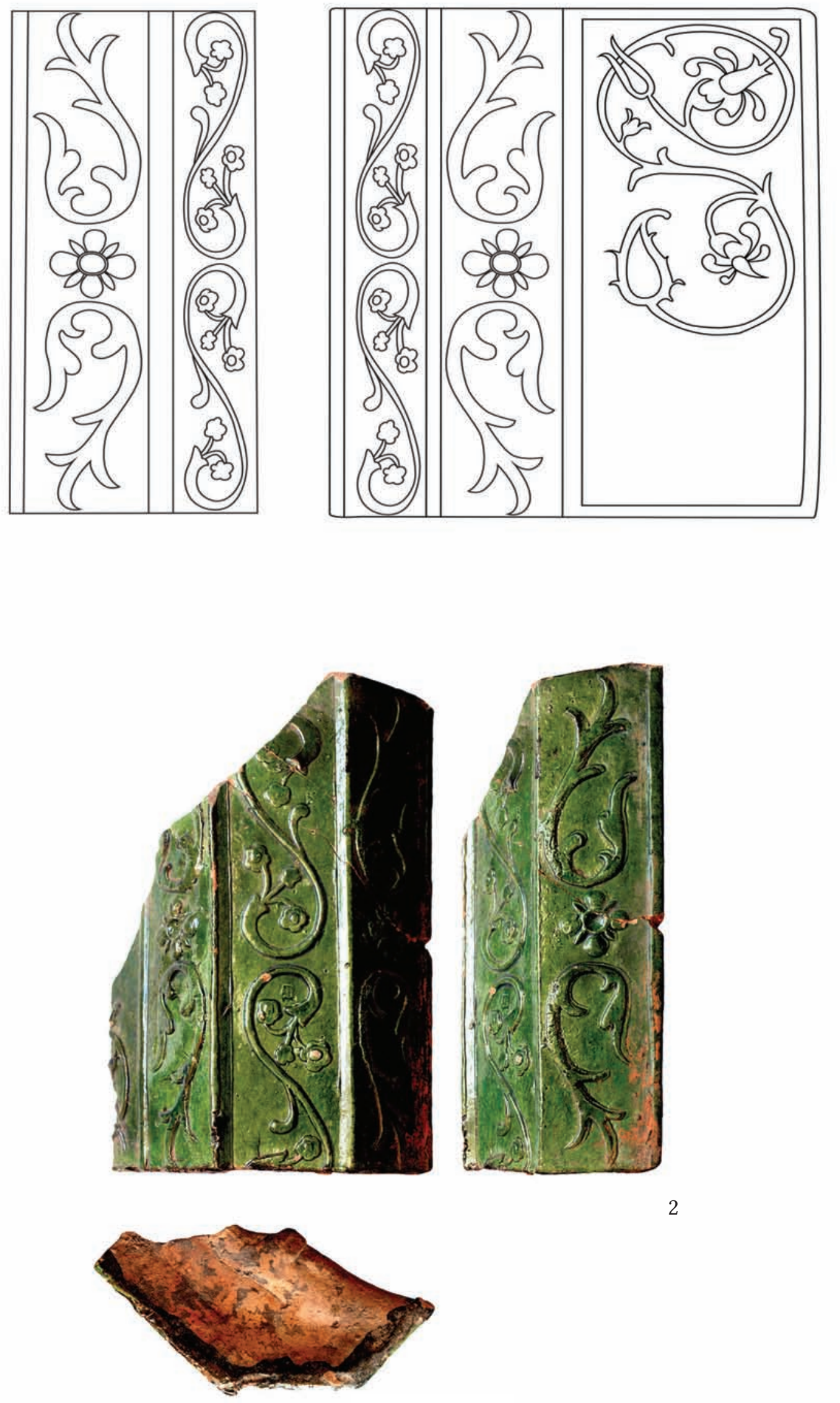

2

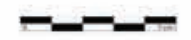

Abb. 29. Die grünglasierte Gruppe auf der Burg Čabrad'. 1-2 - Der Typ 2/4. 

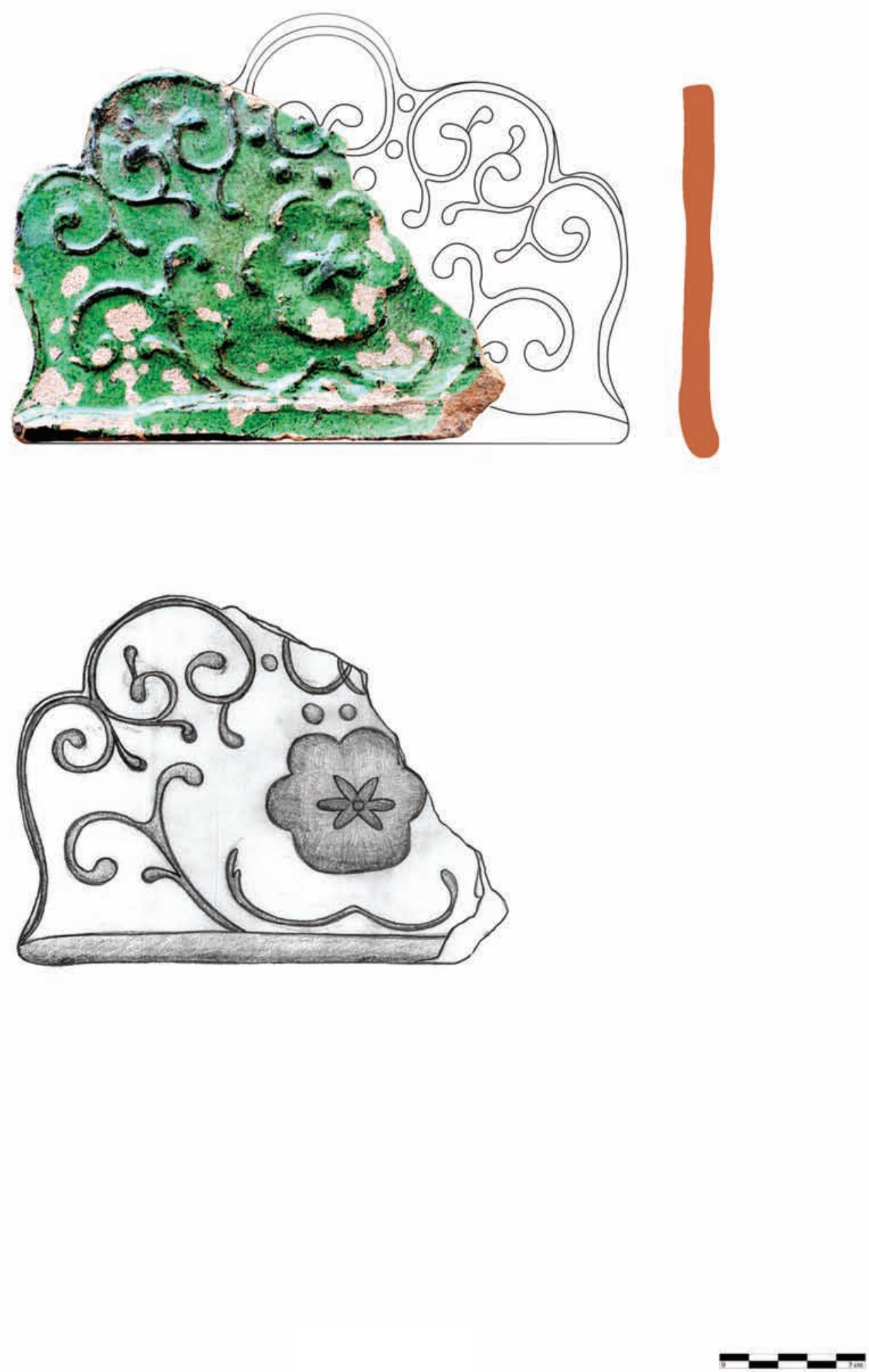

Abb. 30. Die grünglasierte Gruppe auf der Burg Čabrad. Der Typ 2/5. 

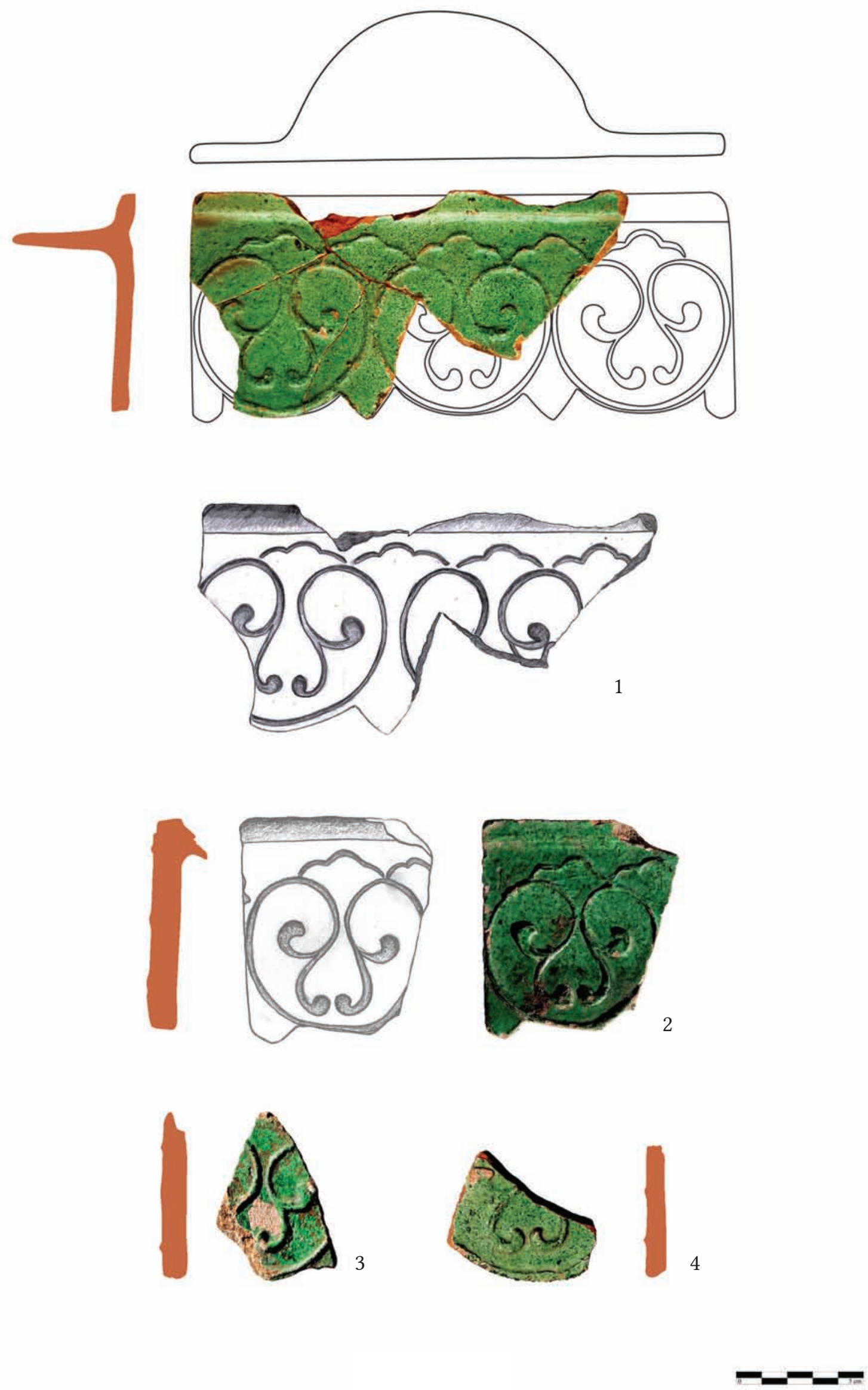

Abb. 31. Die grünglasierte Gruppe auf der Burg Čabrad. 1-4 - Der Typ 2/6. 

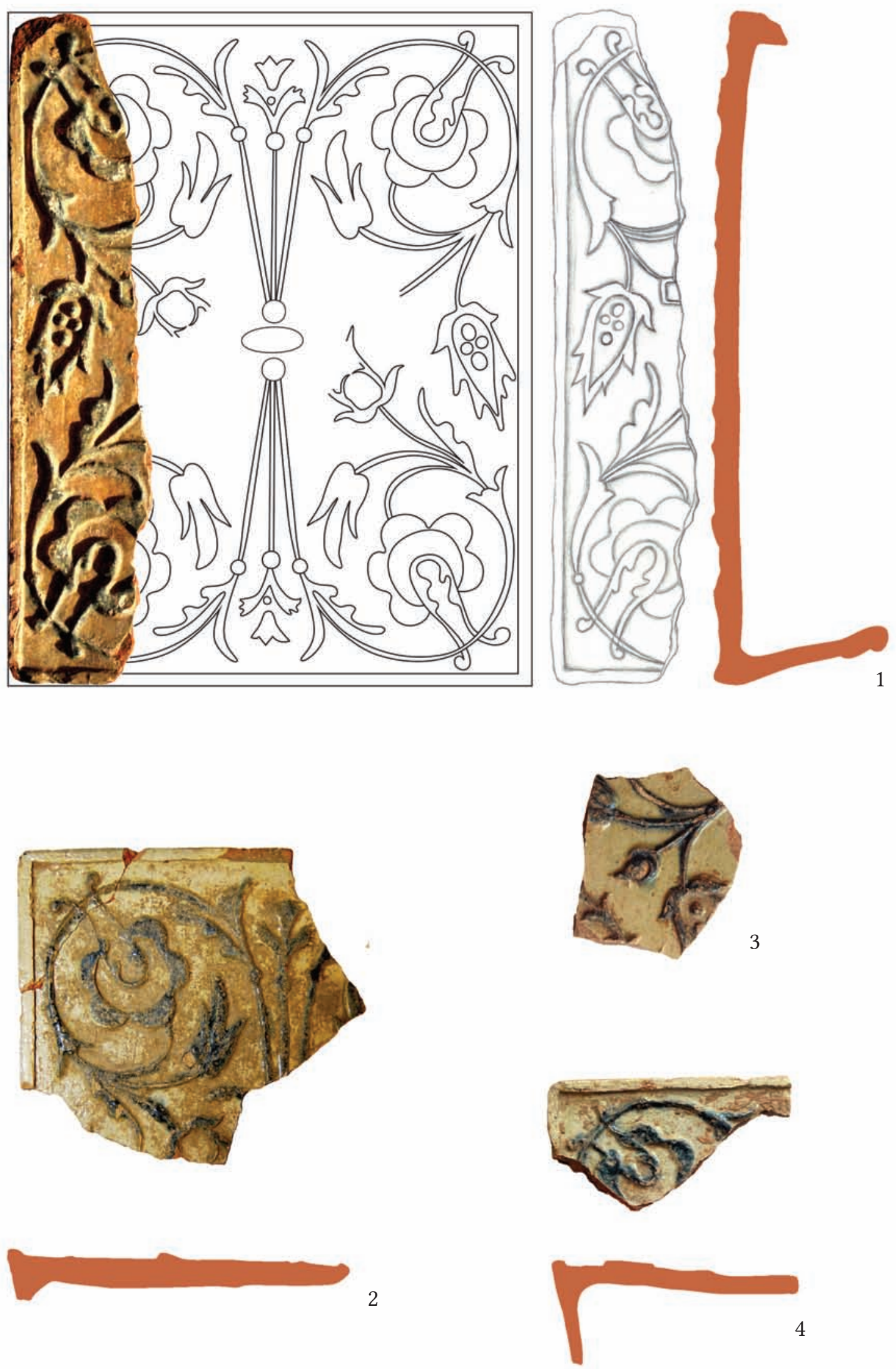

Abb. 32. Imitation der Fayencekacheln auf der Burg Čabrad. 1-4 - Der Typ 3/1. 

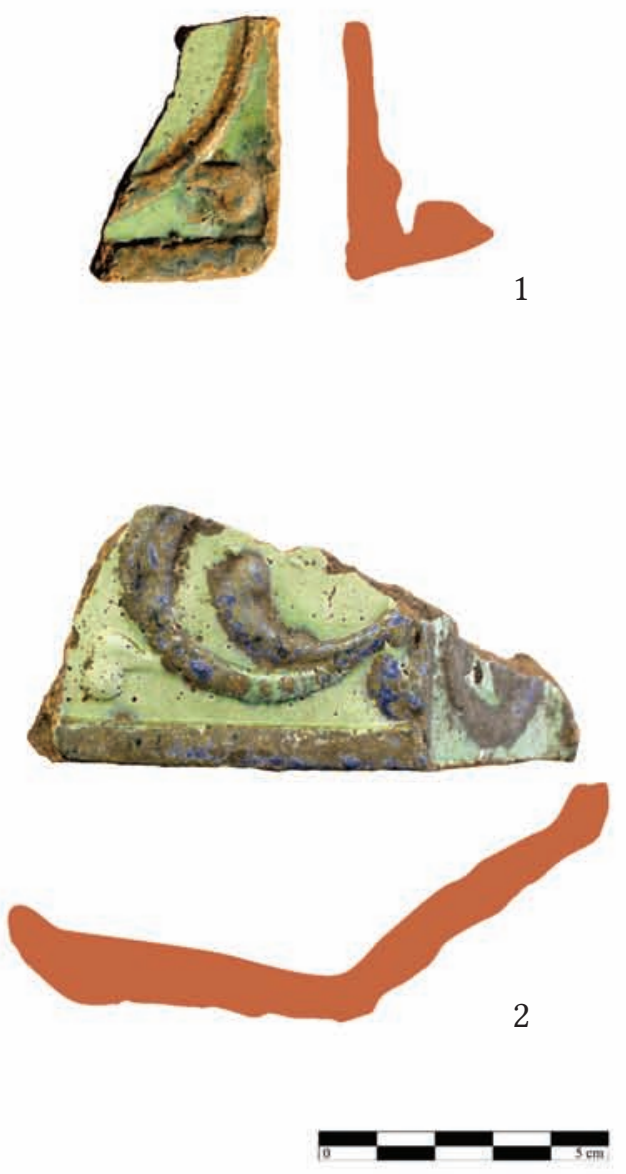

Abb. 33. Imitation der Fayencekacheln auf der Burg Čabrad. 1-2 - Der Typ 3/2. 


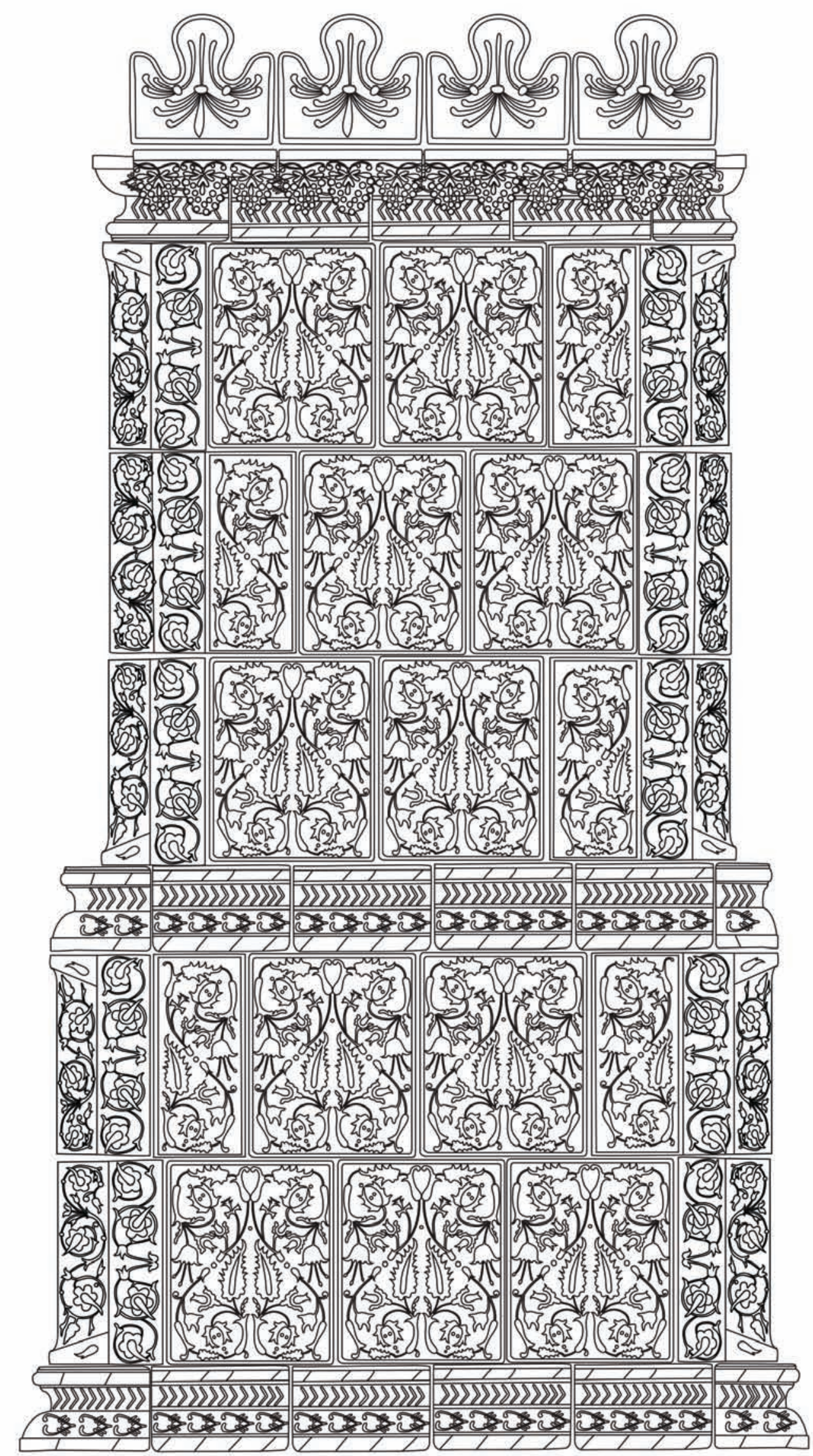

Abb. 34. „Habaner“ Ofenkacheln auf der Burg Čabrad. Die Rekonstruktion aufgrund des Typs 1/1. 


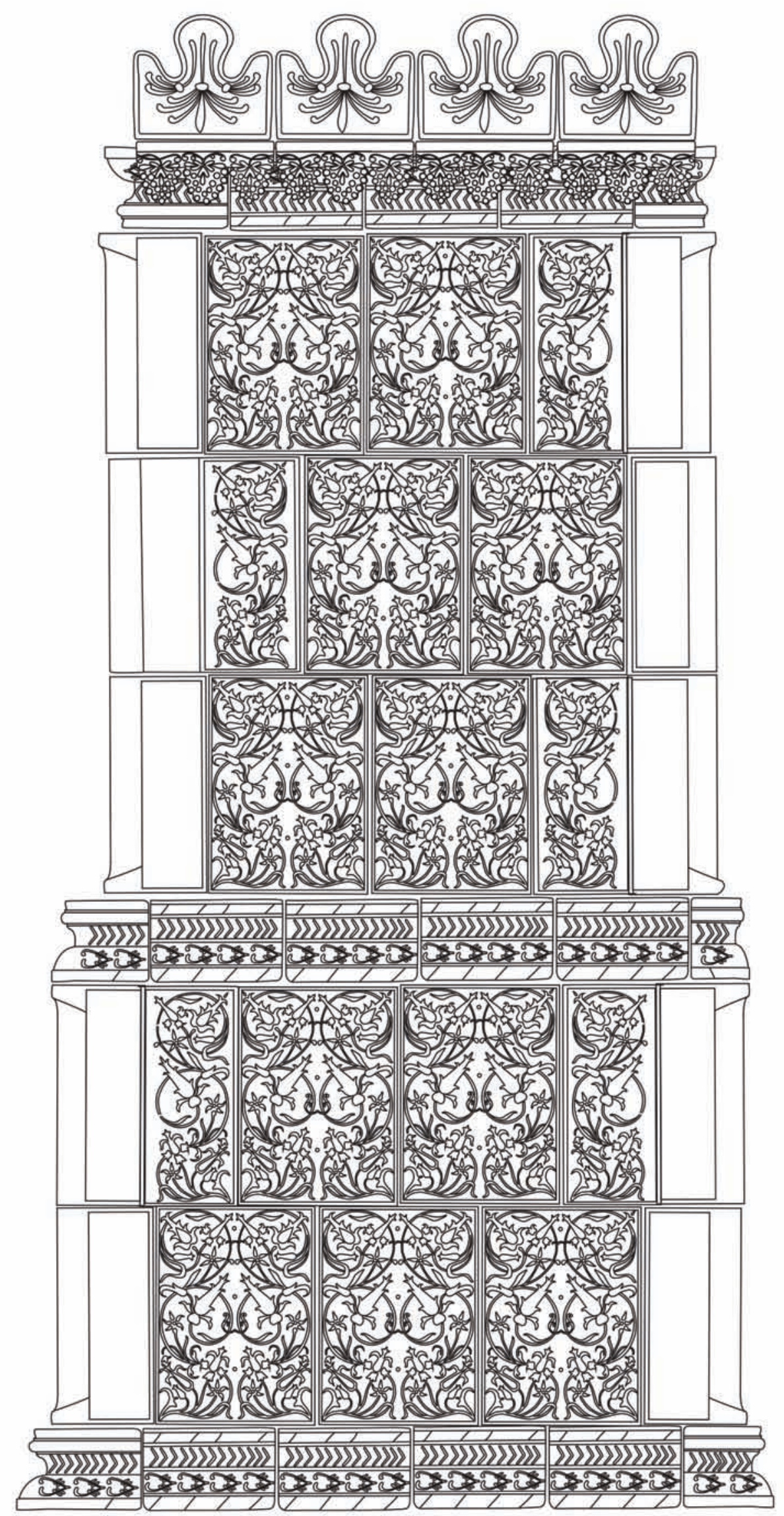

Abb. 35. „Habaner“ Ofenkacheln auf der Burg Čabrad’. Die Rekonstruktion Aufgrund des Typs 1/3. 

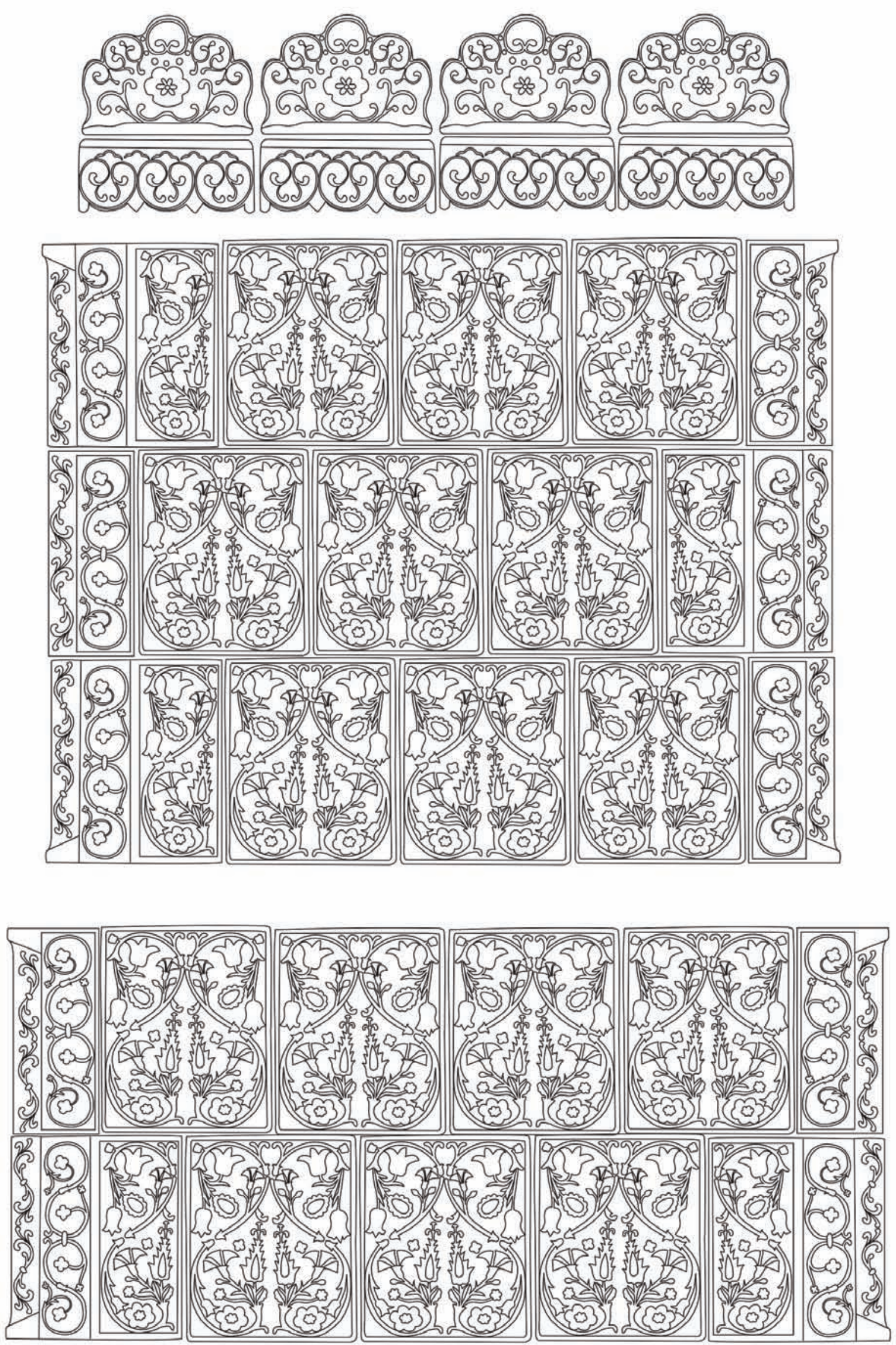

Abb. 36. „Habaner“ Ofenkacheln auf der Burg Čabrad’. Die Rekonstruktion Aufgrund des Typs 2/1. 


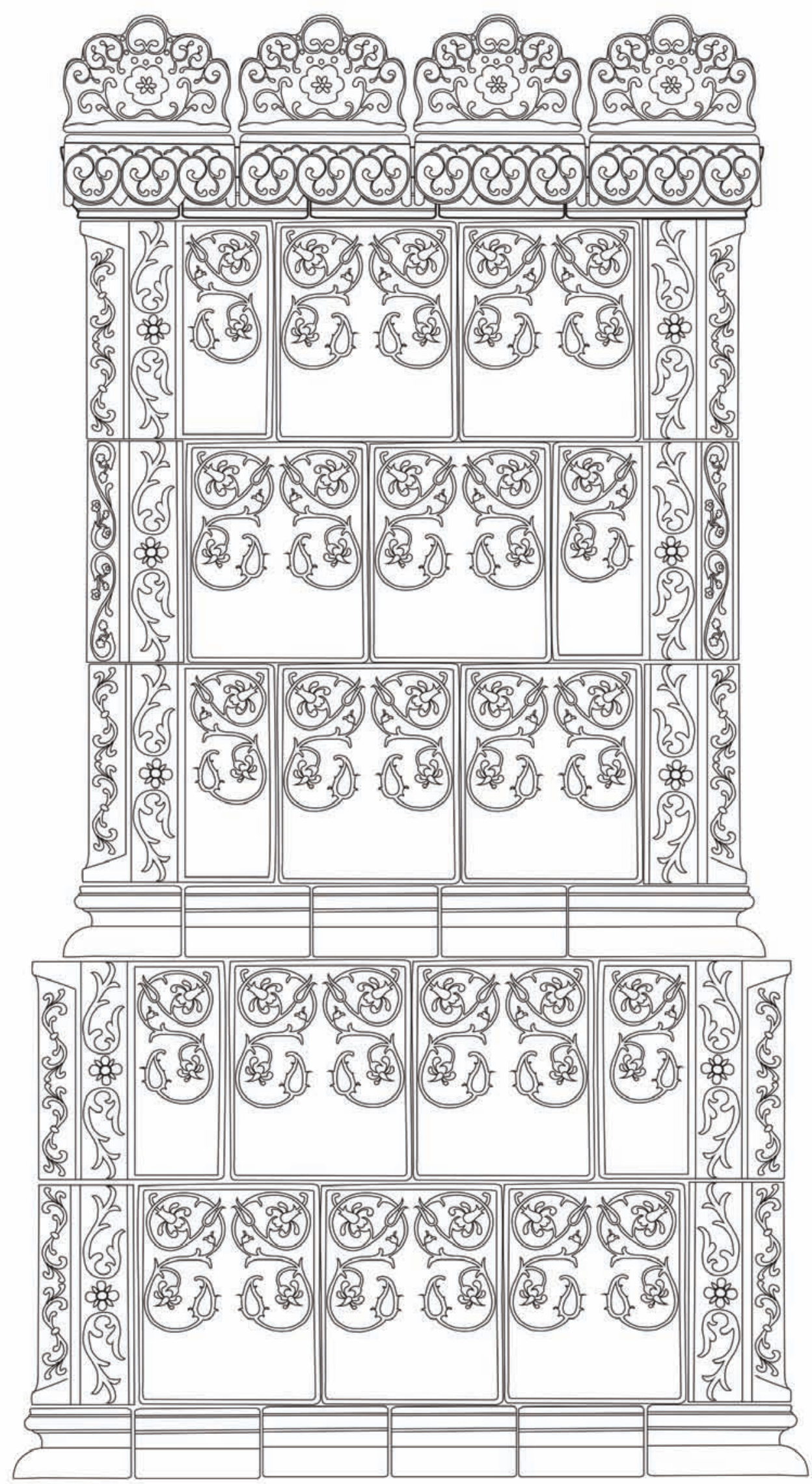

Abb. 37. „Habaner“ Ofenkacheln auf der Burg Čabrad. Die Rekonstruktion Aufgrund des Typs 2/3. 